\title{
Device simulation of all-perovskite four-terminal tandem solar cells: towards $33 \%$ efficiency
}

\author{
Ajay Singh ${ }^{1,2}$ (D) and Alessio Gagliardi ${ }^{1, *}$ \\ ${ }^{1}$ Department of Electrical and Computer Engineering, Technical University of Munich, Arcisstraße 21, 80333 Munich, Germany \\ ${ }^{2}$ Department of Physics and Materials Science, University of Luxembourg, Luxembourg City 1511, Luxembourg
}

Received: 7 June 2021 / Received in final form: 14 June 2021 / Accepted: 18 October 2021

\begin{abstract}
Inorganic-organic hybrid perovskites offer wide optical absorption, long charge carrier diffusion length, and high optical-to-electrical conversion, enabling more than $25 \%$ efficiency of single-junction perovskite solar cells. All-perovskite four-terminal (4T) tandem solar cells have gained great attention because of solutionprocessability and potentially high efficiency without a need for current-matching between subcells. To make the best use of a tandem architecture, the subcell bandgaps and thicknesses must be optimized. This study presents a drift-diffusion simulation model to find optimum device parameters for a $4 \mathrm{~T}$ tandem cell exceeding $33 \%$ of efficiency. Optimized subcell bandgaps and thicknesses, contact workfunctions, charge transport layer doping and perovskite surface modification are investigated for all-perovskite $4 \mathrm{~T}$ tandem solar cells. Also, using real material and device parameters, the impact of bulk and interface traps is investigated. It is observed that, despite high recombination losses, the $4 \mathrm{~T}$ device can achieve very high efficiencies for a broad range of bandgap combinations. We obtained the best efficiency for top and bottom cell bandgaps close to $1.55 \mathrm{eV}$ and $0.9 \mathrm{eV}$, respectively. The optimum thickness of the top and bottom cells are found to be about $250 \mathrm{~nm}$ and $450 \mathrm{~nm}$, respectively. Furthermore, we investigated that doping in the hole transport layers in both the subcells can significantly improve tandem cell efficiency. The present study will provide the experimentalists an optimum device with optimized bandgaps, thicknesses, contact workfunctions, perovskite surface modification and doping in subcells, enabling high-efficiency all-perovskite $4 \mathrm{~T}$ tandem solar cells.
\end{abstract}

Keywords: Perovskite solar cell / four-terminal tandem / drift-diffusion / doping / trap-assisted recombination / surface modification / contact workfunction

\section{Introduction}

Inorganic-organic hybrid perovskites (IOHPs) have emerged as promising photovoltaic material because of their strong optical absorption, high optical to electrical conversion, defect-tolerance, and long-range charge carrier diffusion lengths [1-3]. Furthermore, bandgap tunability and solution processability enables IOHPs to develop a potential alternative photovoltaic technology over the conventional solar cell technologies [3-7]. IOHP-based solar cells (PSCs) have exceeded 25\% [8] of power conversion efficiency (PCE), making this one of the fastest-growing solar cell technology. Moreover, PSCs can be made lightweight, semitransparent and flexible, which attract commercialization of this technology $[3,7,9]$. There have been consistent efforts to improve the efficiency, stability and durability of PSCs by using defect

\footnotetext{
* e-mail: alessio.gagliardi@tum.de
}

and contact passivation, interface engineering, and post treatment methods [10-15].

Although perovskite solar cell technology is rapidly developing, low-cost electricity generation is desired in order to compete with existing solar cell technologies. The electricity generation cost can be brought down by two methods; by extremely low-cost fabrication, or by high output power generation. Power generation by a solar cell is limited by its charge carrier generation and collection efficiencies. A single-junction solar cell has radiative efficiency limit of about $33.7 \%$ of PCE [16]. A single absorber cannot efficiently absorb the full solar spectrum. To surpass the single-junction theoretical (radiative) PCE limit, a multijunction approach should be adopted, i.e., multijunction solar cells. In a multijunction solar cell, multiple absorber layers are used with different bandgaps. Multijunction solar cells can achieve higher efficiencies by absorbing successive ranges of the solar spectrum in a stack of solar cells with decreasing bandgaps. Tandem solar cells are type of multijunction solar cells, consisting of two 
subcells with different bandgap absorbers; a top cell with wide bandgap absorber, and a bottom cell with a low bandgap absorber. High energy part of the solar spectrum is absorbed by the wide bandgap top cell. The solar spectrum below the bandgap of the top cell is transmitted to the bottom cell consisting of a low bandgap absorber.

II-VI and III-V compound-based multijunction solar cells show very high efficiencies $[8,17,18]$. However, they need high thermal budget and intensively controlled environment for single-crystal fabrication methods, leading to high manufacturing cost of photovoltaic modules. Most of IOHPs show low optical absorption for energies below the bandgap and very high absorption at energies above the bandgap [19], making them a suitable choice for subcells of a tandem cell. Due to their absorption selectivity and high optical absorption (energies above the bandgap), the sunlight can be absorbed by a thin layer of perovskite, i.e., $\simeq 1 \mu \mathrm{m}$ or even less. Furthermore, solution processability makes IOHPs easy to integrate with existing solar cells (i.e., $\mathrm{Si}, \mathrm{GaAs}$ ) as a subcell in a tandem device $[20,21]$.

Perovskite/silicon tandem solar cells have demonstrated high efficiencies $[8,22-25]$, but the technology is still far from commercialization due to the cost-ineffectiveness and device instability. To produce low-cost solar electricity, low-temperature and solution-processable thin-film-based tandem solar cells are desired. Perovskite/organic tandem cells offer a potentially low-cost fabrication, but large opencircuit voltage loss in the organic cell limits the tandem cell efficiency [26-28].

IOHP-based fully-perovskite tandem cells (PTSCs) have great potential due to the simple fabrication process, and high power-conversion efficiency [25,29-34]. To meet the absorption spectrum required for a tandem architecture, perovskite bandgap can be fine-tuned by compositional engineering $[4,5]$, which offers a great advantage in using IOHPs in a low bandgap bottom cell as well a wide bandgap top cell. However, most of the research in PSCs revolves around single-junction solar cells. In contrast, PTSCs have not been studies to that extend.

In a tandem cell, the top and bottom cells (hereafter called subcells) can be connected in different electrical configurations. The tandem cell efficiency depends on how the subcells are configured electrically and optically. If the subcells are connected in an electrically-series connection, the configuration is known as a two-terminal (2T) tandem. In a $2 \mathrm{~T}$ configuration, current matching is required between both the subcells; therefore, the tandem efficiency strongly depends on the subcell bandgaps and thicknesses, and the energy alignment throughout the tandem device $[29,31,32,35]$. The $2 \mathrm{~T}$ tandem output-current is limited by the subcell operating at a lower current. However, the operating voltage of the tandem cell is the sum of the subcell operating-voltages at equal current. To obtain the current matching, it is needed to carefully choose the bandgaps, absorber thicknesses, and contact workfunctions $[33,35,36]$.

If the subcells are mechanically stacked and are electrically independent, the configuration is known as four-terminal (4T) tandem. In a $4 \mathrm{~T}$ configuration, since there is no current matching required, the $4 \mathrm{~T}$ efficiency is much less sensitive to subcell bandgaps than the $2 \mathrm{~T}$ design
$[25,34,37]$. Also, the subcells can be independently fabricated and later can be coupled optically. Furthermore, possible use of an optical splitter gives an opportunity to optimize each subcell individually without depositing transparent contacts during fabrication $[30,36,38]$. Possible independent fabrication of subcells enables to integrate a perovskite subcell with inorganic, organic, dye-sensitized and perovskite subcells.

Although any bandgap combination can be used in a $4 \mathrm{~T}$ tandem configuration, it is required to optimize subcell bandgaps and thicknesses to fully utilize the solar spectrum. Some of the bandgap combinations have already been used experimentally to demonstrate $4 \mathrm{~T}$ perovskite tandem cells [30,32,39-41], but the reported efficiencies are still far from the possible theoretical limit of about $45 \%$ $[34,42]$. Various loss mechanisms hampering the tandem cell efficiency still remain unexplored. Material and device optimization, interface engineering, surface passivation, charge transport layer doping, and the role of contacts are not very well studied for PTSCs. More research is needed to develop and commercialize PTSC technologies.

There have been theoretical studies to investigate tandem cell efficiency considering ideal absorbers (not necessarily perovskites) and ideal device structures [42-45]. Most of these studies have been based on either a particular set of bandgaps or a fixed set of thicknesses. To study allperovskite tandem solar cells, Rajagopal et al. [31] presented Shockley-Queisser detailed balance calculations to analyze the efficiency of $4 \mathrm{~T}$ and $2 \mathrm{~T}$ tandem cells. To account for the optical losses, they assumed fixed $81 \%$ and $90 \%$ external quantum efficiency (EQE) of bottom and top subcells, respectively. Leijtens et al. [34] calculated tandem cell efficiencies by assuming ideal diode equation and $100 \%$ EQE above the bandgap. Recently, Tan et al. [37] presented stochastic Monte Carlo simulations to obtain $4 \mathrm{~T}$ tandem cells exceeding $24 \%$ of efficiency. All the aforementioned studies on perovskite $4 \mathrm{~T}$ tandems focus on specific aspects of the material or device considering several assumptions. The charge transport in tandem solar cells is very complex and is not very well understood.

Here, we present a TiberCAD-based drift-diffusion model to study the roles of various subcell parameters, i.e., bandgaps, thicknesses, charge transport layer doping, contact workfunction and perovskite interface modification. A one-dimensional drift-diffusion is implemented by using real material and device parameters from the literature. The study is built upon our previous work for single-junction, and all-perovskite $2 \mathrm{~T}$ terminal tandem solar cells [35]. We investigate the subcells individually while achieving optical-coupling by feeding the top cell filtered light to the bottom cell. We vary the individual subcell material and device parameters to obtain the current-voltage $(J-V)$ characteristics. We also tune both the subcell's parameters together to obtain efficiency contour plots for $4 \mathrm{~T}$ tandem cells. Theoretically possible $4 \mathrm{~T}$ tandem efficiencies are calculated for various bandgaps and thicknesses combinations. Then, trap-assisted losses are introduced to calculate practically achievable efficiencies. Optimized subcell thicknesses and bandgaps are obtained to realize the maximum efficiency of a $4 \mathrm{~T}$ tandem cell. Furthermore, we analyze the role of contact 
workfunctions and doping levels in the charge transport layer to increase the tandem efficiency further. Finally, perovskite interface modification is studied to maximize the $4 \mathrm{~T}$ tandem efficiency.

\section{Simulation model}

A finite-element drift-diffusion model is implemented in TiberCAD [46,47]. The model can perform 3-dimensional simulations, and has already been used to simulate organic solar cells [48], organic field-effect transistors [49], PSCs $[14,50]$ and dye-sensitized solar cells [51]. Within the model,

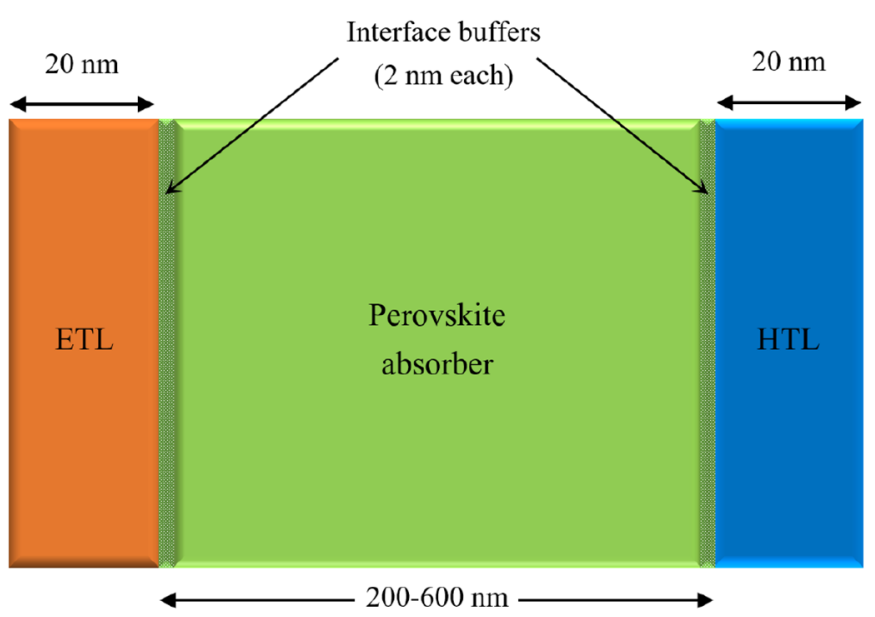

Fig. 1. 1D simulation model for a perovskite solar cell. Interface buffer regions are made up of the same material as the perovskite absorber. The buffers can host defect states and traps, leading to recombination losses.

(a)

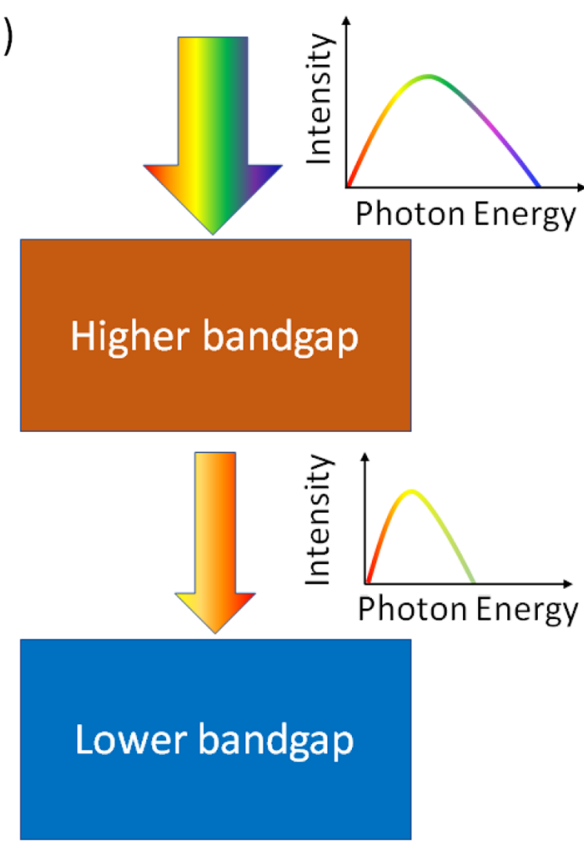

Poisson and drift-diffusion equations are solved simultaneously for electrons, holes, and trapping centers, considering the light absorption and the charge carrier generation-recombination processes. A perovskite solar cell is mapped into a one-dimensional (1D) system, and therefore, we solve the drift-diffusion model over 1D space. The subcells, i.e., top and bottoms cells are simulated independently. Like our previous studies [35,50,52], the interface traps are defined in two buffer regions (2 each) connected to the perovskite and charge transport layers. Figure 1 shows a 1D perovskite solar cell model for a subcell in an all-perovskite $4 \mathrm{~T}$ tandem solar cell.

As shown in Figure 2a, the light filtered from the top cell is incident on the bottom cell. The high-energy photons are absorbed by the top cell consisting of a large bandgap perovskite absorber. The lower energy part of the solar spectrum is transmitted to the bottom cell consisting of a low bandgap perovskite absorber.

Upon light exposure, electron-hole pairs are generated in perovskite absorber, which dissociate into free electrons and holes by using thermal energy. Due to the concentration gradient and under the influence of a built-in electric field, the electrons travel towards the electron transport layer (ETL), and the holes travel towards the hole transport layer (HTL). Transport of these charge carriers is governed by concentration-gradient-induced diffusion and electrically-induced drift forces. The transport is defined by the following set of coupled drift-diffusion equations:

$$
\left\{\begin{array}{l}
\nabla \cdot(\varepsilon \nabla \Phi)=-q\left(n-p+N_{a}^{-}-N_{d}^{+}+n_{t}^{-}-n_{t}^{+}\right) \\
\nabla \cdot\left\{\mu_{n} n\left(\nabla \Phi_{n}\right)\right\}=G-R \\
\nabla \cdot\left\{\mu_{p} p\left(\nabla \Phi_{n}\right)\right\}=R-G
\end{array}\right.
$$

(b)

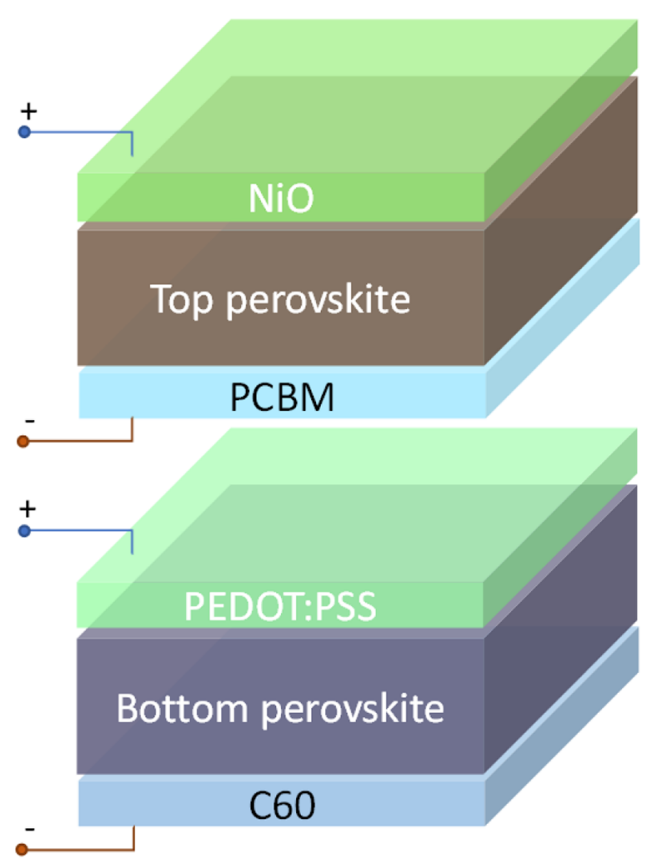

Fig. 2. (a) Spectrum splitting in a tandem solar cell, and (b) all-perovskite four-terminal (4T) tandem solar cell representation. The material layers in (b) correspond to the materials used in this study. 
where $\varepsilon$ is the material permittivity, $\Phi$ is the electrostatic potential, and $q$ represent the elementary charge. $n, p, N_{d}^{+}$, and $N_{a}^{-}$, represent the densities of electrons, holes, ionised donor impurities, and ionized acceptor impurities, respectively. Electron and hole trapping is goverened by donor trap density $\left(n_{t}^{+}\right)$, and, acceptor traps density $\left(n_{t}^{-}\right)$, respectively. Electrical mobility of electrons and holes are represented by $\mu_{n}$ and $\mu_{p}$, respectively. Electron and hole diffusion coefficients are calculated by using Einstein relation, $D_{n, p}=k T \mu_{n, p} / q$. $\Phi_{p}$ and $\Phi_{n}$ govern the (variable) electrochemical potentials of holes and electrons, respectively. The charge carrier generation $G$, in the perovskite absorber is governed by the Lambert-Beer model, and is given by:

$$
G(x)=\int_{\lambda_{\min }}^{\lambda_{\max }} \varphi(\lambda) \alpha(\lambda) e^{-\alpha(\lambda) x} d \lambda
$$

where $G(x)$ defines the generation rate at position $x . \varphi(\lambda)$ and $\alpha(\lambda)$ represent the solar light intensity, and the absorption coefficient at wavelength $\lambda$, respectively. Optical generation rate is calculated by using the AM 1.5 standard spectrum between $350 \mathrm{~nm}$ and $1500 \mathrm{~nm}$.

To calculate the absorption spectrum $(\alpha(\lambda))$ within the perovskite layers, a direct bandgap nature is considered for the perovskite absorbers [53,54]. Considering parabolic band approximation, optical absorption is given by [55]:

$$
\alpha(\lambda)=A^{*} \sqrt{\frac{h c}{\lambda}-E_{g}},
$$

where $h$ represent the Planck's constant. $c$ defines the light velocity in vacuum, and $E_{g}$ is the perovskite bandgap. $A^{*}$ is defined by the electron and hole effective masses. We assume the electron and hole effective masses to be constant, and therefore use $A^{*}=10 \mathrm{~cm}^{-1} \sqrt{\mathrm{eV}}$ as a fitting parameter [35]. We would like to mention that the " $n-k$ " based transfer matrix models could be even more accurate to calculate the optical properties and hence the charge carrier generation rates. However, in literature, the " $n$ and $k$ " values are available only for a few perovskites, i.e., $\mathrm{CH}_{3} \mathrm{NH}_{3} \mathrm{PbX}_{3}(\mathrm{X}=\mathrm{I}, \mathrm{Cl}, \mathrm{Br})$ or $\mathrm{CH}_{3} \mathrm{NH}_{3} \mathrm{SnI}_{3}$. Here, we present efficiency maps for the bandgaps ranging between $0.8 \mathrm{eV}$ and $2.0 \mathrm{eV}$. Therefore, we adopt the approach governed by equations (3) and (2). The simulation results explained in different sections are fairly close to the experimentally obtained results [56-60].

The charge carrier recombination rate, $R$ is governed by direct (bimolecular: radiative) and trap-assisted nonradiative recombinations. Direct recombination rate is defined as:

$$
R_{\text {direct }}=C_{\text {dir }}\left(n p-n_{i}^{2}\right),
$$

where $C_{\text {dir }}$ is the direct recombination rate constant, and $n_{i}$ is the equilibrium carrier density. The role of trap is modeled by defining trap-assisted nonradiative recombination rate, given by a Shockley-Read-Hall recombination rate, as follows [61]:

$$
R_{S R H}=\frac{n p-n_{i}^{2}}{\left(n+n_{i} e^{E^{*} / k_{B} T}\right) \tau_{p}+\left(p+p_{i} e^{-E^{*} / k_{B} T}\right) \tau_{n}},
$$

where $E^{*}=E_{\text {trap }}-\left(E_{c}+E_{v}\right) / 2$ is the energy level of the trap with respect to the midband energy. $\tau_{p}$ and $\tau_{n}$ define the trapping times of holes and electrons, respectively. Higher trap density results in more trapping and hence smaller trapping time, and vice versa. Midgap don`or and acceptor traps are considered as the SRH is shown to be most effective for the traps located in the middle of the bandgap [62].

The drift-diffusion simulation parameters are summarized in Table 1. Several studies have employed $\mathrm{C}_{60}$ and PCBM electron transport layers [63,64], and NIO and PEDOT:PSS hole transport layers [65-67]. For this reasons, we use these materials as charge transport layers in our simulations. High charge-carrier mobilities are considered in ETL and the HTL to ensure the tandem cell performance is not limited by the charge transport layers. To ensure the hole-blocking nature of ETL, the hole mobility in ETL is considered to be 5 orders of magnitude smaller than the electron mobility. Similarly, the electron mobility in the HTL is considered to be 5 orders of magnitude smaller than the hole mobility. To collect the charge carriers at the contacts, Schottky-type contacts are considered. A contact connected to the HTL (ETL) is regarded as a cathode (anode) of the subcell. Several metal halide perovskites exhibit a relative permittivity (dielectric constant) in the range 15-25, and many of them have it close to 20 [68-70]. For this reason, we fix the perovskite relative permittivity to be 20 . We observed that, changing the dielectric permittivity has a poor dependence on the efficiency as the charge carriers are easily separated (from the electron-hole pairs) and transferred to the charge transport layers. Cathode and anode workfunctions are chosen based on the typically available cathode and anode material (i.e, indium-tin oxide, fluorine-tin oxide, $\mathrm{Ag}, \mathrm{Au}$ ). Several studies report transparent conductive indium-tin oxide (ITO) bandgap between $-3.9 \mathrm{eV}$ and $-5.5 \mathrm{eV}$ [71-75]. In a tandem device, ITO is a choice of material for cathode, and it's workfunction depends on the film synthesis method, and pre/post treatment processes, i.e, cleaning (by organic solvents, ultrasonic bath, $\mathrm{Ar}$ sputtering and reactive ion etching, mixture of boiling deionized water, hydrogen peroxide, and ammonia) [71-73], and surface modification [74,76,77]. Fluorine-tin oxide (FTO) is another transparent conductive material for the contacts which exhibits a bandgap between $-4.4 \mathrm{eV}$ and $-5.55 \mathrm{eV}[71,78,79]$. In many perovskite solar cells, FTO/ glass is used as substrate, where FTO serves as anode contact. Considering the fact that the cathode energy level should be higher than that of highest occupied molecular orbital (HOMO) or valence band of the HTL, a cathode workfunction of $-4.9 \mathrm{eV}$ is used initially. The Anode energy level should be below the lowest unoccupied molecular orbital (LUMO) or conduction band of the ETL, therefore, an anode workfunction of $-4.5 \mathrm{eV}$ is used in the initial 
Table 1. List of parameters used in the drift-diffusion simulation. Parameters marked with asterisks $\left(^{*}\right)$ are varied during the simulations. In case of multiple references, approximated values are chosen from the gives references.

\begin{tabular}{|c|c|c|c|}
\hline Parameter & Value & Units & References \\
\hline Electron mobility in perovskite & 5 & $\mathrm{~cm}^{2} /(\mathrm{Vs})$ & {$[2,80,81]$} \\
\hline Hole mobility in perovskite & 5 & $\mathrm{~cm}^{2} /(\mathrm{Vs})$ & {$[2,80,81]$} \\
\hline Perovskite relative permitivity & 20 & - & {$[68-70]$} \\
\hline PCBM bandgap & 1.8 & $\mathrm{eV}$ & {$[82]$} \\
\hline PCBM LUMO & -5.9 & $\mathrm{eV}$ & {$[83]$} \\
\hline$n$ doping in PCBM & $1 \times 10^{14}$ & $\mathrm{~cm}^{-3}$ & fit. \\
\hline PCBM relative permitivitty & 3.9 & - & {$[84]$} \\
\hline Electron mobility in PCBM & 1 & $\mathrm{~cm}^{2} /(\mathrm{Vs})$ & fit. \\
\hline NIO bandgap & 2.8 & $\mathrm{eV}$ & {$[85]$} \\
\hline NIO valence band & -5.3 & $\mathrm{eV}$ & {$[85]$} \\
\hline NIO relative permitivitty & 8 & - & {$[86]$} \\
\hline$p$ doping in $\mathrm{NiO}$ & $1 \times 10^{15}$ & $\mathrm{~cm}^{-3}$ & $*$ \\
\hline Hole mobility in NIO & 1 & $\mathrm{~cm}^{2} /(\mathrm{Vs})$ & {$[87,88]$} \\
\hline $\mathrm{C}_{60}$ bandgap & 2 & $\mathrm{eV}$ & [89] \\
\hline $\mathrm{C}_{60} \mathrm{HOMO}$ & -6.2 & $\mathrm{eV}$ & [90] \\
\hline Electron mobility in $\mathrm{C}_{60}$ & 1 & $\mathrm{~cm}^{2} /(\mathrm{Vs})$ & [91] \\
\hline $\mathrm{C}_{60}$ relative permitivitty & 3.03 & - & [92] \\
\hline$n$ doping in $\mathrm{C}_{60}$ & $1 \times 10^{15}$ & $\mathrm{~cm}^{-3}$ & fit. \\
\hline PEDOT:PSS bandgap & 3 & $\mathrm{eV}$ & {$[93]$} \\
\hline PEDOT:PSS HOMO & -5 & $\mathrm{eV}$ & {$[93]$} \\
\hline PEDOT:PSS relative permitivitty & 3 & - & [94] \\
\hline$p$ doping in PEDOT:PSS & $1 \times 10^{16}$ & $\mathrm{~cm}^{-3}$ & $*$ \\
\hline Hole mobility in PEDOT:PSS & 1 & $\mathrm{~cm}^{2} /(\mathrm{Vs})$ & fit. \\
\hline Cathodes Fermi level & -4.9 & $\mathrm{eV}$ & {$[73,75,74]^{*}$} \\
\hline Anodes Fermi level & -4.5 & $\mathrm{eV}$ & {$[78,79,71]^{*}$} \\
\hline Direct recombination constant & $1 \times 10^{-10}$ & $\mathrm{~cm}^{-3} \mathrm{~s}^{-1}$ & {$[95]$} \\
\hline
\end{tabular}

simulations. Later, the role of the change in workfunction is studied in detail.

Most of the hybrid perovskites show good ambipolar mobilities; therefore, equal mobility is chosen for electrons and holes within the perovskite layer $[1,2,32,80]$. Moreover, changing the bandgap by substituting iodine with chlorine or bromine has minor effects on the mobilities, and many of the hybrid perovskites show charge carrier mobilities between $1 \mathrm{~cm}^{2} /(\mathrm{Vs})$ to $20 \mathrm{~cm}^{2} /(\mathrm{Vs})[2,80,82]$. For these reasons, we consider equal electron and hole mobilities of $5 \mathrm{~cm}^{2} /(\mathrm{Vs})$ in the perovskite layers. We start with $\mathrm{CH}_{3} \mathrm{NH}_{3} \mathrm{PbI}_{3}\left(E_{g}=1.55 \mathrm{eV}\right)$ as a reference for top cell $(\mathrm{NiO} /$ Perovskite/PCBM) parameterization. The fitting parameters are chosen such that the calculated shortcircuit current density, open-circuit voltage and efficiency of the subcells are in good agreement with the experimental values [59]. $\mathrm{FASnI}_{3}\left(E_{g}=1.24 \mathrm{eV}[60]\right)$ is considered as reference for parameterization for the bottom cell. The stand-alone bottom cell (PEDOT:PSS/Perovskite/ $\mathrm{C}_{60}$ ) parameters are chosen such that the photovoltaic performance, mainly the short circuit current density is in good agreement with experimental studies [56-58]. However, the reported open-circuit voltage values for $\mathrm{FASnI}_{3}$ are lower compared to predicted theoretical values. Other bandgaps are obtained by symmetrically tuning the conduction and valence bands of the perovskite. The top and the bottom cells are simulated independently. The tandem cell performance is analyzed by parameterizing one subcell at a time. The $4 \mathrm{~T}$ tandem efficiency is calculated by summing up the efficiencies of the subcells.

\section{Results and discussion}

We start with simulating an ideal (no trap-assisted recombination losses) top cell to obtain $J-V$ characteristics. The $J-V$ characteristics are studied as a function of bandgap and thickness of the perovskite layer. Then, the $J-V$ characteristics are calculated for (ideal) filtered bottom cells; the light filtered by a top cell is incident on the bottom cell. We refer to top (bottom) cell "perovskite absorber" thickness and bandgap as the top (bottom) cell thickness and bandgap, respectively. Using the $J-V$ characteristics, maximum power point efficiencies are calculated for ideal subcells and a $4 \mathrm{~T}$ tandem cell. Later, traps are introduced within the buffers (interface 


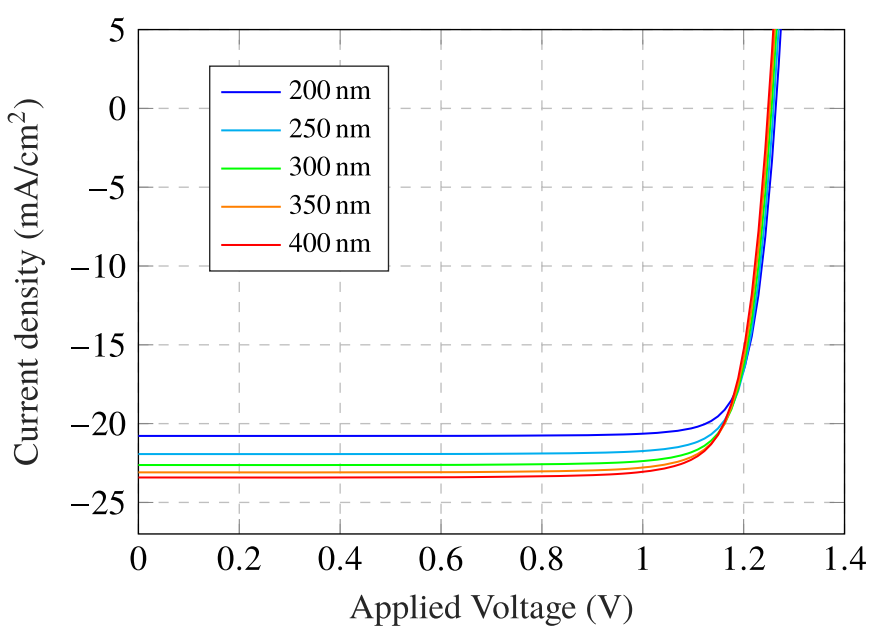

Fig. 3. Simulated $J-V$ characteristics for top cells with varying perovskite thickness. The perovskite bandgap is fixed to $1.55 \mathrm{eV}$.

traps) and the perovskite film (bulk traps) as nonradiative recombination centers. Efficiency contours are plotted for various thicknesses and bandgap combinations of the bottom and top cells.

\subsection{No trap-assisted recombination losses}

Figure 3 shows simulated top cell $J-V$ characteristics varying the perovskite layer thickness at a fixed bandgap of 1.55. The chosen bandgap is close to the bandgap of wellknown $\mathrm{CH}_{3} \mathrm{NH}_{3} \mathrm{PbI}_{3}$ perovskite. With increasing the perovskite thickness from $200 \mathrm{~nm}$ to $350 \mathrm{~nm}$, the shortcircuit current density increases, while the open-circuit voltage remains almost unchanged. The calculated shortcircuit densities are in the range of experimentally observed values, and therefore justify the simulation parameters for various layers and the device as a whole [59,96-98]. Increasing the perovskite thickness beyond $350 \mathrm{~nm}$ doesn't change the cell performance much. This gives an indication of the upper limit of the top cell thickness for the given bandgap.

The light filtered by a $350 \mathrm{~nm}$ thick and $1.55 \mathrm{eV}$ bandgap top cell is incident on bottom cells of bandgap of $1.0 \mathrm{eV}$. Figure 4 shows the $J-V$ characteristics for filtered bottom cells with various thicknesses. The bottom cell thickness is varied from $200 \mathrm{~nm}$ to $600 \mathrm{~nm}$. It is observed that the $J_{\mathrm{sc}}$ increases while increasing the bottom cell thickness. On the other hand, the $V_{\text {oc }}$ decreases with increasing the perovskite thickness. However, the change in $V_{\text {oc }}$ is rather small compared to the change in $J_{\mathrm{sc}}$. For the bottom cell thickness beyond $550 \mathrm{~nm}$, the photovoltaic performance parameters do not change significantly.

Keeping the bottom cell bandgap and thickness fixed $(1.0 \mathrm{eV}$ and $350 \mathrm{~nm}$, respectively), bottom cell $J-V$ characteristics are calculated while varying the top cell bandgap. Figure 5 shows $J-V$ characteristics for bottom cells filtered by $350 \mathrm{~nm}$ thick top cells. Increasing the bandgap leads to low light absorption by the top cell, and hence more light is filtered to the bottom cell. This results in increased bottom cell $J_{\mathrm{sc}}$ with increasing the top cell

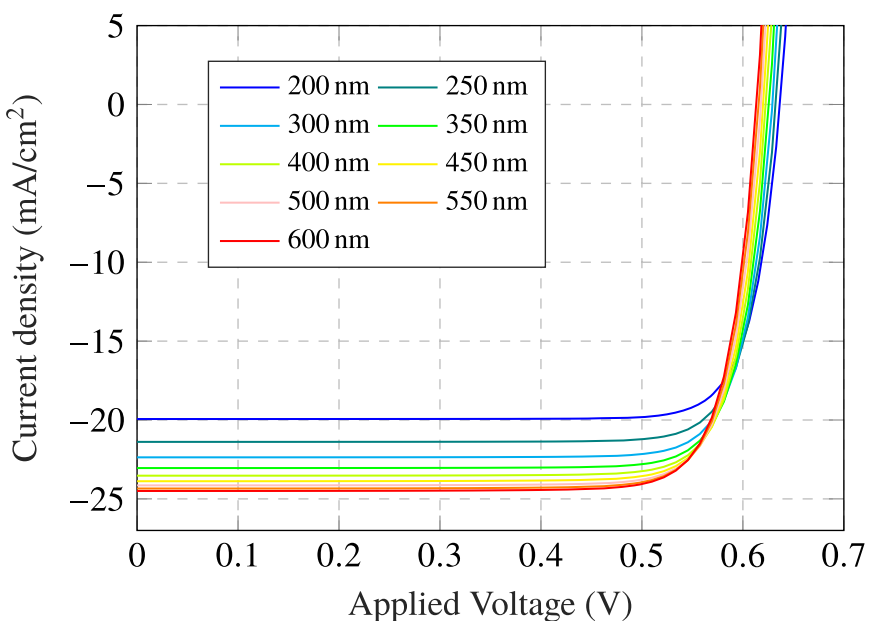

Fig. 4. Simulated $J-V$ curves for the bottom cells filtered with a $350 \mathrm{~nm}$ thick, $1.55 \mathrm{eV}$ bandgap of top cell. The bottom cell bandgap is fixed at $1.0 \mathrm{eV}$.

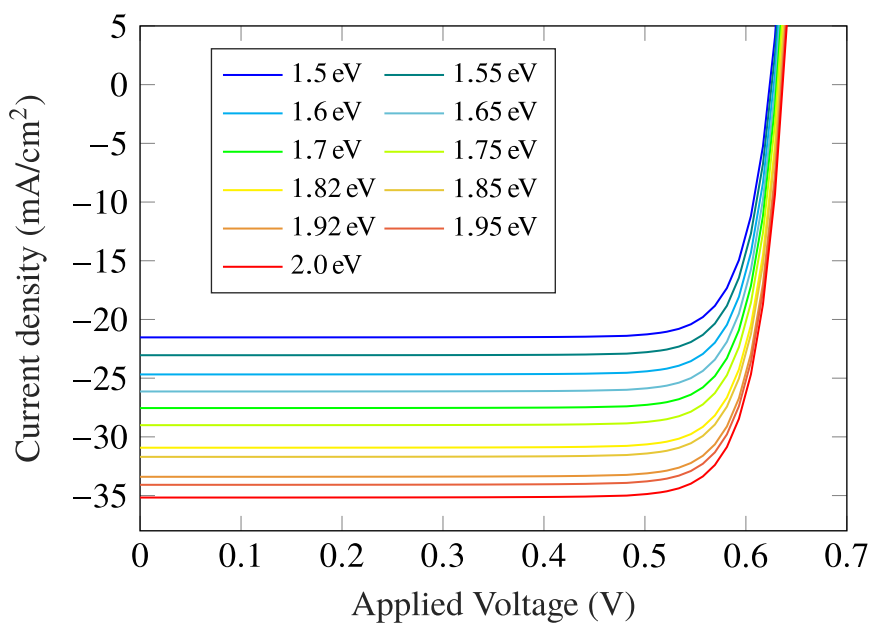

Fig. 5. Simulated $J-V$ characteristics for a filtered bottom cell with varying the top cell bandgap. The top cell thickness is fixed at $350 \mathrm{~nm}$. The bottom cells thickness and bandgaps are fixed at $350 \mathrm{~nm}$ and $1.0 \mathrm{eV}$, respectively.

bandgap. The bottom cell $V_{\text {oc }}$ also increases slightly. This could occur due to the cell voltage dependence on the light intensity. However, the change in voltage is small compared to the change in current density.

Now, the top cell bandgap, top cell thickness and the bottom cell thickness are fixed to $1.55 \mathrm{eV}, 350 \mathrm{~nm}$ and $350 \mathrm{~nm}$, respectively. The $J-V$ characteristics are calculated by varying the bottom cell bandgap, as shown in Figure 6 . The bottom cell voltage and current density change with the bottom cell bandgap. Similar to a standalone single-junction cell, the current density increases, and the voltage decreases while decreasing the bandgap. A low bandgap leads to more light absorption and therefore produces more current. Since the output voltage is sensitive to the valence and conduction band-edges of the perovskite, the output voltage shows a strong dependence on the bandgap. 


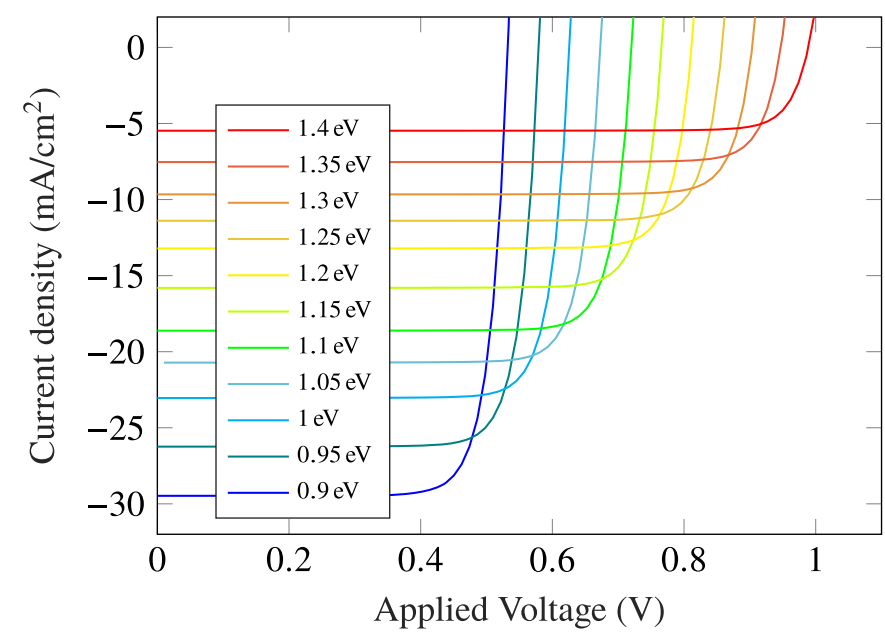

Fig. 6. Simulated $J-V$ characteristics for $350 \mathrm{~nm}$ thick filtered bottom cells of different bandgaps. The top cell bandgap and thickness are fixed at $1.55 \mathrm{eV}$ and $350 \mathrm{~nm}$, respectively. Increasing the bottom cell bandgap result in increases current and reduced output voltage.

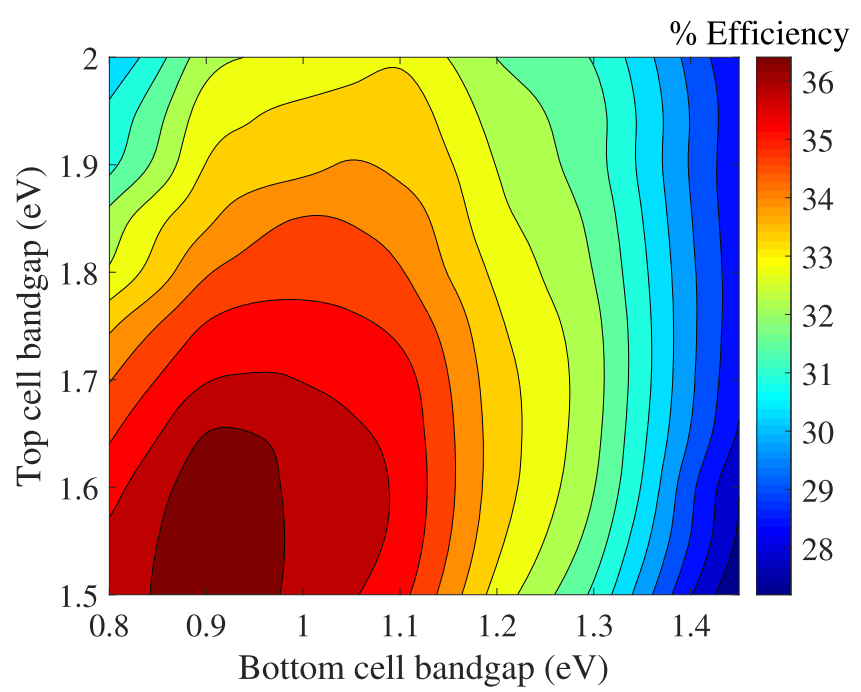

Fig. 7. 4T tandem solar cell efficiency for different bandgaps of top and bottom cells, without considering trap-assisted recombination losses. The thicknesses for both the top and bottom cells are fixed at $350 \mathrm{~nm}$.

So far, the $J-V$ characteristics were calculated to analyze the impact of thicknesses and bandgap on the performance of the individual subcells. The changes in subcell's voltage and current density lead to change the tandem cell output power and efficiency. In the next analysis, the top and bottom cell thickness are fixed, and their bandgaps are varied to analyze the efficiency of a $4 \mathrm{~T}$ tandem cell. The bottom cell bandgap is varied between $0.8 \mathrm{eV}$ and $1.45 \mathrm{eV}$, and the top cell bandgap is varied between $1.55 \mathrm{eV}$ and $2.0 \mathrm{eV}$. Figure 7 shows the calculated $4 \mathrm{~T}$ tandem cell efficiencies for fixed top and bottom cell

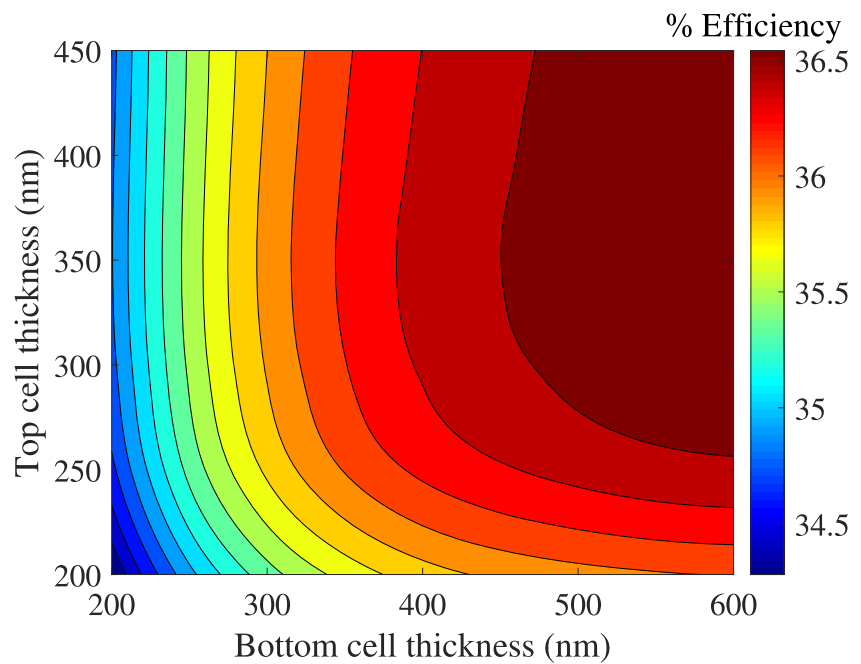

Fig. 8. $4 \mathrm{~T}$ tandem solar cell efficiency for different thicknesses of top and bottom cells, without considering trap-assisted recombination losses. The bandgaps of the top and bottom cells are fixed at $1.55 \mathrm{eV}$ and $1.0 \mathrm{eV}$, respectively.

thicknesses at $350 \mathrm{~nm}$. A maximum of $\simeq 37 \%$ efficiency is obtained for a bottom cell bandgap of $0.9 \mathrm{eV}$ and top cell bandgap of $1.5 \mathrm{eV}$. to $1.55 \mathrm{eV}$. Increasing the bottom cell bandgap leads to less optical absorption; therefore, the tandem efficiency decreases. Increasing the top cell bandgap results in more light filtered to the bottom cell; however, the top cell underperforms due to low light absorption, and therefore the tandem efficiency decreases. About $33.5 \%$ of tandem efficiency is observed close to a top cell bandgap of $1.55 \mathrm{eV}$ (corresponding to the well known $\mathrm{CH}_{3} \mathrm{NH}_{3} \mathrm{PbI}_{3}$ perovskite), and a bottom cell bandgap of $1.2 \mathrm{eV}$ (close to Si bandgap). This bandgap combination is a promising for developing $\mathrm{Si} /$ perovskite and fullyperovskite tandem solar cells.

This is evident from the efficiency plot that, to realize the best use of solar spectrum, a low bandgap bottom cell (about $1.0 \mathrm{eV}$ ) is desired along with a wide bandgap top cell. Numerous perovskite materials have been proposed for the top cell, with bandgaps ranging from $1.55 \mathrm{eV}$ to $2.3 \mathrm{eV}$ $[4,11,20,99]$. In contrast, there are less number of options available for low bandgap perovskites for a bottom cell. Tin (Sn)-based and mixed-cation perovskites show bandgaps in the range $0.9 \mathrm{eV}$ to $1.3 \mathrm{eV}[20,40,100]$. Therefore, Sn-based perovskites have potential application in all-perovskite tandem photovoltaics.

For our next analysis, two bandgap combinations are chosen to analyze the tandem efficiency as a function of subcell thickness. One set of bandgaps is chosen corresponding to $1.55 \mathrm{eV}$ and $1.0 \mathrm{eV}$ of bandgaps of the top and bottom cells, respectively. $4 \mathrm{~T}$ tandem cell efficiencies are calculated by varying the subcell thicknesses, as shown in Figure 8. It is observed that the chosen bandgap combination has the potential to exceed $36.5 \%$ of efficiency.

Increasing the bottom cell thickness results in more absorption by this cell and hence in more output current. Therefore, the tandem efficiency increases with increasing 


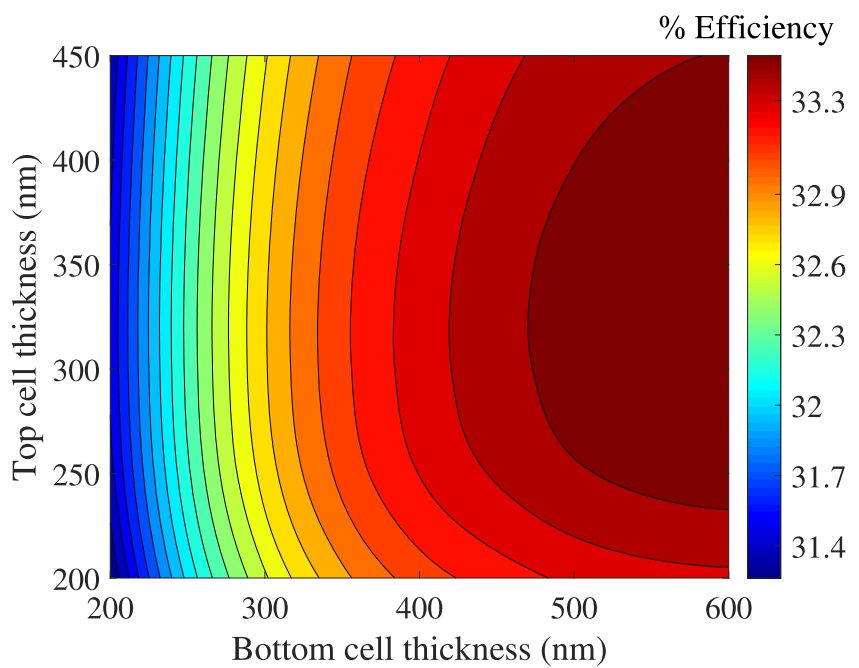

Fig. 9. 4T tandem solar cell efficiency for different thicknesses of top and bottom cells, with top and bottom cell bandgaps fixed at $1.82 \mathrm{eV}$ and $1.20 \mathrm{eV}$, respectively. Trap-assisted recombination losses have not been considered.

the bottom cell thickness. The increment in the efficiency is more prominent for the thicknesses between $200 \mathrm{~nm}$ to $300 \mathrm{~nm}$. Beyond $300 \mathrm{~nm}$, the current increment becomes rather small. Optimum efficiency is obtained for a bottom cell thickness of $\simeq 500 \mathrm{~nm}$. On the other hand, the tandem efficiency shows a poor dependence on the top cell thickness as compared to the bottom cell thickness. Increasing the top cell thickness beyond $\sim 280 \mathrm{~nm}$ does not change the tandem efficiency. This could be due to the fact that the top cell absorption saturates beyond this thickness. Therefore, the charge carrier generation and the output current density do not increase. Increasing the perovskite thickness beyond diffusion length will lead to suppress the charge carrier transport and hence the output current. In this case, since the traps are not considered, the diffusion lengths are much higher than $450 \mathrm{~nm}$. Therefore a drop in efficiency is not observed while increasing the top cell thickness upto $450 \mathrm{~nm}$. This is clear from here that, for the given bandgap combination, about $300 \mathrm{~nm}$ top and about $500 \mathrm{~nm}$ bottom cells are required to obtain theoretically optimum tandem efficiency.

Another set of bandgaps is chosen close to the experimentally demonstrated bandgaps for all-perovskite tandem cells $[20,30,32,39,41]$. The top and bottom cell bandgaps are chosen to be $1.82 \mathrm{eV}$ and $1.2 \mathrm{eV}$. The $4 \mathrm{~T}$ tandem efficiencies are calculated for various subcell thicknesses. As shown in Figure 9, the maximum achievable efficiency reduces to about $33.5 \%$, as opposed to $\simeq 36.5 \%$ for $(1.55 \mathrm{eV}$ and $1.0 \mathrm{eV})$. This could be because the solar spectrum below $1.2 \mathrm{eV}$ is not absorbed, and is filtered out by the bottom cell. Also, the top cell in this case (which is the current limiting cell) operates at lower current, as compared to $1.55 \mathrm{eV}$ top cell in the previous case. Interestingly, a thinner top cell is required to get the optimum efficiency. The optimum thicknesses are found to be about $250 \mathrm{~nm}$ and $\simeq 500 \mathrm{~nm}$ for the top and bottom cells, respectively.

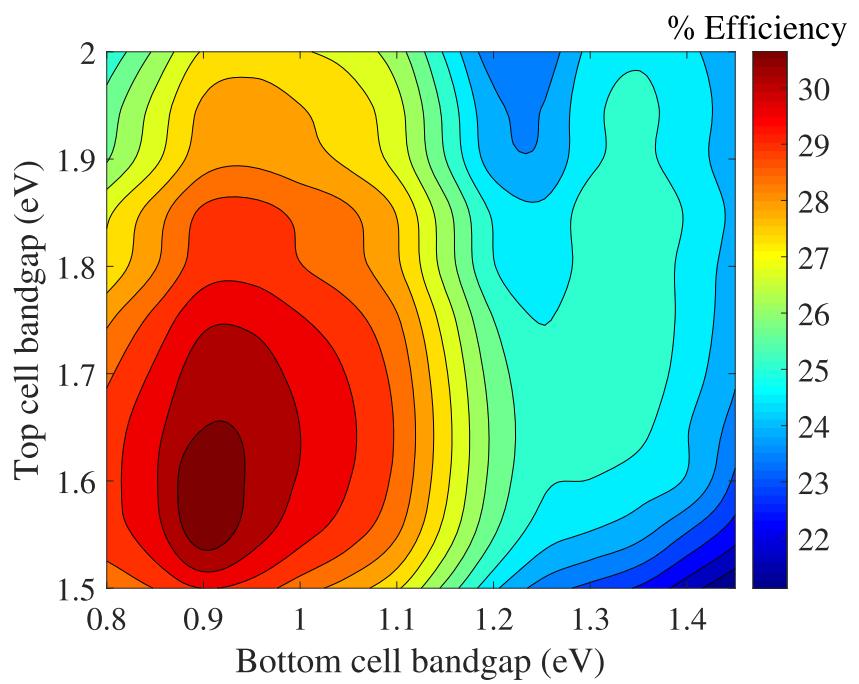

Fig. 10. 4T tandem solar cell efficiency for different bandgaps of top and bottom cells with trap-assisted recombinations. The thicknesses for both the top and bottom cells are fixed at $350 \mathrm{~nm}$. Both bulk and interface traps are considered in top and bottom cells.

\subsection{The impact of trap-assisted nonradiative recombinations}

So far, ideal devices were considered as the top and bottom cells without trap-assisted recombinations. It is well known that IOHP films consist of grain boundaries and other defects, which lead to trap-assisted recombinations [101-103]. Also, interfaces between the perovskite and the charge transport layers host the traps, and they have been found to be the dominating recombination centers in the perovskite cells [104-106]. Despite other losses, the trapassisted nonradiative recombinations have been considered to be the main losses limiting the cell performance [80,102,105].

In our next analysis, we introduce trap-assisted nonradiative recombinations in both the top and bottom cells. The recombination is determined by trapping times of electrons and holes as defined by equation (5). The trap density and hence the trapping time depends on the absorber material quality and the device fabrication scheme. In this study, to keep the analysis simple, equal trapping times are considered in both the subcells. Since the interfaces consist of more traps, a smaller trapping time is assigned for the interfaces in contrast to the bulk of perovskite film. Within the interface buffers, $\tau_{n}=\tau_{p}=1 \times 10^{-9}$ is considered. In the bulk perovskite film, $\tau_{n}=\tau_{p}=5 \times 10^{-7}$ is considered [95].

Considering trap-assisted recombination, $4 \mathrm{~T}$ tandem efficiency is calculated for various combinations of thicknesses and bandgaps of subcells. Figure 10 shows tandem cell efficiencies for different bandgap combinations. As compared to the ideal cells (see Fig. 7), the maximum achievable efficiency reduces to $31.2 \%$. Also, the optimum bandgap shifts to a higher top cell bandgap, i.e., $1.55 \mathrm{eV}$ to $1.6 \mathrm{eV}$. However, the bottom cell optimum bandgap remains almost constant about $0.9 \mathrm{eV}$. Interestingly, for 


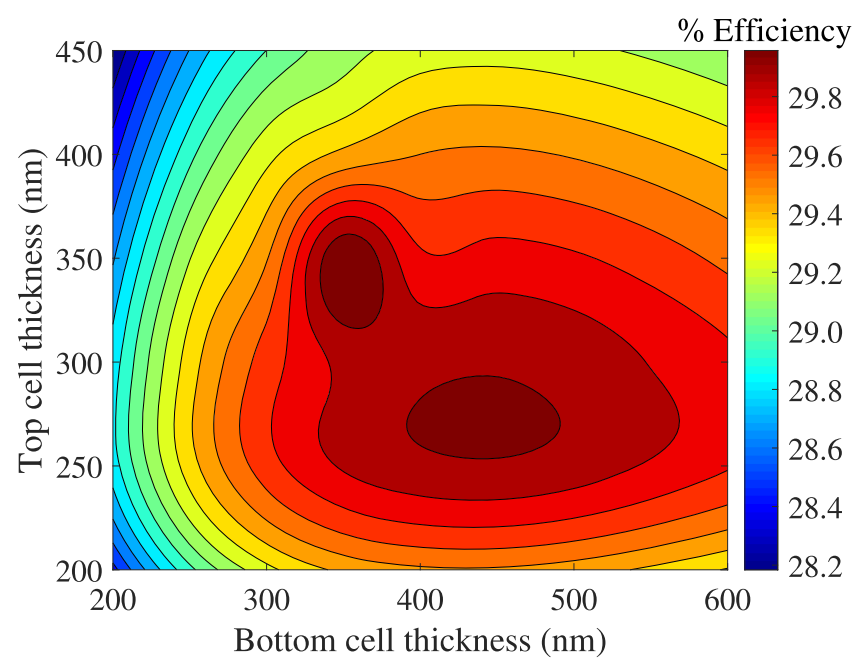

Fig. 11. $4 \mathrm{~T}$ tandem solar cell efficiency for different thicknesses of top and bottom cells considering trap-assisted recombination losses. The top and bottom cell bandgaps are fixed at $1.55 \mathrm{eV}$ and $1.0 \mathrm{eV}$, respectively. Traps are considered in the interface buffers and the bulk perovskite film of both the subcells.

some of the bottom cell bandgaps (i.e., $1.15 \mathrm{eV}$ to $1.35 \mathrm{eV}$ ), at a fixed top cell bandgap (i.e., $1.82 \mathrm{eV}$ ), the tandem efficiency initially decreases, then increases, and then again decreases. This could be due to the choice of parameters in the study. Moreover, the relative change in the efficiency is small (i.e., for bottom cell bandgap of $1.35 \mathrm{eV}$ versus $1.4 \mathrm{eV})$. In the simulations, energy levels of the charge transport layers and the contact workfunctions are fixed, while the perovskite bandgap is changed symmetrically (same amount of change in the conduction and valence bands). The tandem efficiency can slightly change if different charge transport layers are used.

For two bandgap combinations, thickness dependence on tandem efficiency is analyzed. Figure 11 shows calculated efficiency for the top and bottom cell bandgaps of $1.55 \mathrm{eV}$ and, $1.0 \mathrm{eV}$, respectively. A maximum of $30.05 \%$ efficiency is obtained for top and bottom cell thicknesses of $350 \mathrm{~nm}$ and $350 \mathrm{~nm}$, respectively. Increasing bottom cell thickness to $450 \mathrm{~nm}$, and simultaneously decreasing the top cell thickness to $250 \mathrm{~nm}$ result in a maximum of $29.94 \%$ tandem efficiency. At a fixed top cell thickness of $250 \mathrm{~nm}$, it is found that increasing the bottom cell thickness beyond $350 \mathrm{~nm}$ does not lead to significant improvement in the tandem efficiency. Increasing the bottom cell thickness leads to more absorption of the available solar spectrum; however, increased thickness result in more nonradiative recombinations in the bottom cell. This correlation between the bottom cell absorption and the nonradiative recombination leads to a particular thickness window correspond to the optimum output efficiency.

Figure 12 shows simulated efficiencies for top and bottom cell bandgaps of $1.82 \mathrm{eV}$ and $1.2 \mathrm{eV}$, respectively. It can be clearly seen that the optimum efficiency shifts to a lower thickness of the top cell. Also, a maximum of $25.4 \%$ of tandem efficiency is obtained for a top cell of $250 \mathrm{~nm}$, in combination with a bottom cell of $350 \mathrm{~nm}$. For $350 \mathrm{~nm}$

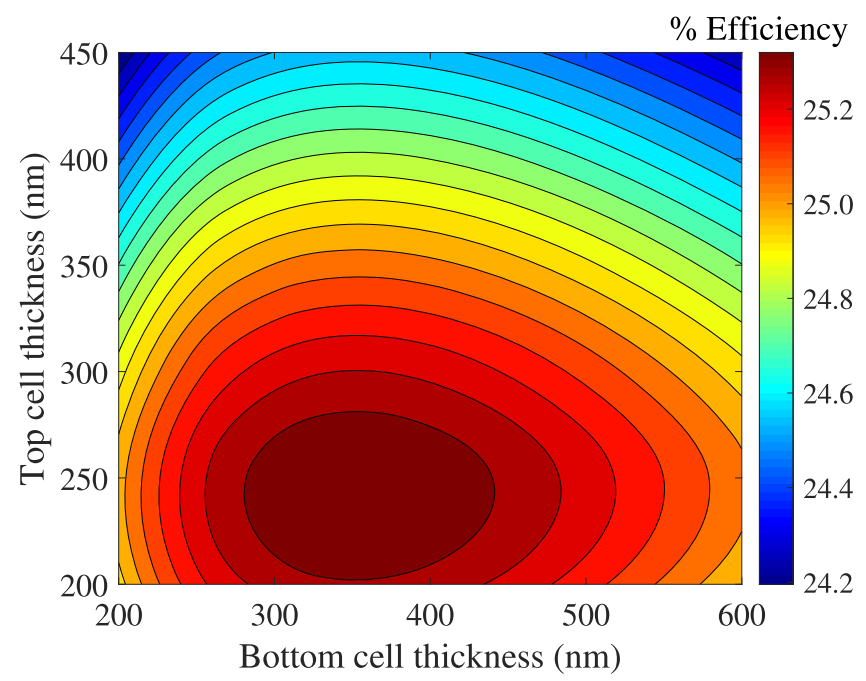

Fig. 12. $4 \mathrm{~T}$ tandem solar cell efficiency for different thicknesses of top and bottom cells considering trap-assisted recombination losses. The top and bottom cell bandgaps are fixed at $1.82 \mathrm{eV}$ and $1.2 \mathrm{eV}$, respectively. Interface and bulk traps are considered in both the subcells.

bottom cell, decreasing the top cell thickness to $200 \mathrm{~nm}$ leads to only a slight decrease in the tandem efficiency $(25.3 \%)$. An increase in the top cell thickness results in reduced tandem efficiency.

Increasing the top cell thickness leads to increased nonradiative recombinations in the top cell, resulting in overall decreases in the tandem efficiency. Since a good amount of light is filtered to the bottom cell (by a top cell of $1.82 \mathrm{eV}$ ), a comparatively thicker bottom cell is desired to absorb the available light. However, at higher bottom cell thickness beyond $\simeq 400 \mathrm{~nm}$, the bottom cell performance is limited by the nonradiative recombinations, and hence the tandem efficiency decreases. Precise control of trap density and charge carrier mobility is always difficult during the fabrication process. Therefore, this is worth mentioning that different trapping strengths $\left(\tau_{\mathrm{n}}, \tau_{\mathrm{p}}\right)$ and charge carrier mobilities in perovskite layer can result in different optimum thicknesses [35].

\subsection{Doping in charge transport layers}

One important merit of a $4 \mathrm{~T}$ configuration over a $2 \mathrm{~T}$ configuration is that, in a $4 \mathrm{~T}$ tandem configuration, the top and bottom cells can be optimized independently. For a single-junction cell, energy alignment throughout the device is important in the transport and collection of photogenerated charge carriers. The energy alignment depends on the conduction and valence bands of each of the material, and the workfunctions of the contact materials used in a cell. Furthermore, the doping level in the charge transport layers determines the Fermi energy level in those layers. The Fermi level plays a crucial role in the charge transport within a solar cell. Doping of charge transport layers has been reported to improve the performance of a single-junction perovskite cell $[98,107]$. In a $4 \mathrm{~T}$ tandem 


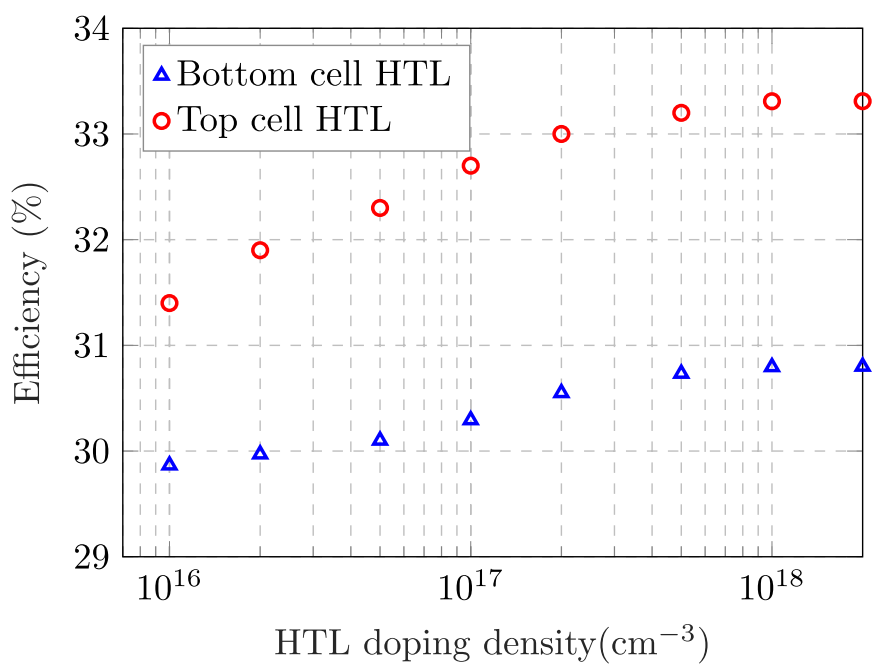

Fig. 13. Calculated tandem efficiency with doping in top and bottom cell hole transport layers. Initially, the top cell doping is fixed at $1 \times 10^{18} \mathrm{~cm}^{-3}$, and the bottom cell efficiency is increased upto $1 \times 10^{18} \mathrm{~cm}^{-3}$. Then, the bottom cell HTL doping is fixed at $1 \times 10^{18} \mathrm{~cm}^{-3}$, and the top cell HTL is doping is varied upto $1 \times 10^{18} \mathrm{~cm}^{-3}$. The top and bottom cell bandgaps are chosen to be $1.55 \mathrm{eV}$ and $1.0 \mathrm{eV}$, respectively. The top and bottom cell thicknesses are fixed at $250 \mathrm{~nm}$ and $350 \mathrm{~nm}$, respectively.

architecture, the subcell charge transport layers can be doped to individually improve the subcells and hence the tandem cell performance.

In this study, we investigate the impact of doping level in the HTL of top and bottom cells. A bandgap combination, $1.55 \mathrm{eV}$ and $1.0 \mathrm{eV}$ (top and bottom cells, respectively) is chosen for the analysis. Taking the efficiency map (Fig. 11) into consideration, the top and bottom cell thicknesses are chosen to be $250 \mathrm{~nm}$ and $350 \mathrm{~nm}$, respectively. Initially, the top cell HTL doping is kept to $1 \times 10^{15} \mathrm{~cm}^{-3}$ (the same as used for all the analysis so far). The bottom cell HTL doping is varied from $1 \times 10^{15} \mathrm{~cm}^{-3}$ to $1 \times 10^{18} \mathrm{~cm}^{-3}$. Calculated $4 \mathrm{~T}$ tandem efficiency is shown by blue marks in Figure 13. An improvement in the bottom cell and consequently in the tandem efficiency is observed upon doping. At a bottom cell HTL doping of $1 \times 10^{18} \mathrm{~cm}^{-3}$, the tandem cell efficiency increases to $30.8 \%$. Beyond $1 \times 10^{18} \mathrm{~cm}^{-3}$, we do not observe much improvement in the output efficiency.

The bottom cell HTL doping is then fixed at $1 \times 10^{18} \mathrm{~cm}^{-3}$, and the top cell HTL doping is increased. With an increase in the top cell HTL doping, the tandem efficiency increases significantly. Upon HTL doping, the improvement in bottom cell efficiency is infact higher than that of bottom cell. This results in higher tandem cell efficiency. For top ell HTL doping of $1 \times 10^{18} \mathrm{~cm}^{-3}$, the tandem cell efficiency exceeds $33 \%$. Beyond $1 \times 1018 \mathrm{~cm}^{-3}$, the efficiency starts drooping. And therefore, we limit our analysis to $2 \times 10^{18} \mathrm{~cm}^{-3}$ of HTL doping. We would like to mention that the optimum doping level also depends on the energy levels of different layers and the contact workfunctions. In this study, a constant-mobility model is employed. However, in an organic charge transport layer, increased doping can result in reduced charge carrier mobility [108]. Therefore, a trade-off can be found between the efficiency increment due to the energy alignment improvement and the decreased mobility. In a tandem cell, both the top cell contacts, and the bottom cell front contact are needed to be optically transparent. There are not many suitable choices available for transparent contacts, mainly for low bandgap perovskite cells. In that case, doping in charge transport can help to find good energy alignment throughout the device.

\subsection{Contact work function}

Workfunctions of the cathode and anode contacts play important role in charge extraction from a solar cell. In a tandem cell, FTO and ITO are commonly used as transparent contact for the top cell contacts and the front contact of the bottom cell. For the maximum efficiency of a cell, an optimum contact workfunction is desired with respect to the perovskite material and the charge transport layers. Workfunction tuning of transparent ITO can be achieved by controlling growth parameters, capacitively coupled plasma [109], and by using amino-functionalized polyfluorene and self-assembled monolayers [74,76,77]. Similarly, FTO workfunction can be tuned by controlling growth parameters, ion-implantation [78] and surface modification techniques $[110,111]$. Also, in the bottom cell, the bottom contact can be replaced by metal contact which is optically opaque. Here, we study the impact of changing the contact workfunctions of the bottom cell while keeping the top cell contacts unchanged. The top and bottom cell thicknesses and bandgaps are kept the same as Section 3.3. Initially, the bottom cell cathode is fixed to $-4.9 \mathrm{eV}$, and the anode workfunction is varied between $-4.1 \mathrm{eV}$ and $-4.5 \mathrm{eV}$. We observe that the tandem cell efficiency increases (from $32.02 \%$ at $-4.1 \mathrm{eV}$ ) to $32.15 \%$ (at $-4.5 \mathrm{eV}$ ). The increase in efficiency can be attributed to increased electron collection at the anode contact. Lowering the energy level of the anode eases the electron injection from the ETL to the anode. To note that a different alignment throughout the cell (energy levels of all the layers and cathode) can result in different trend of tandem efficiecny with respoce to anode energy level. Therefore, the choice of anode material strongly depends on the device architecture. As a next analysis we fix the anode energy level to $-4.4 \mathrm{eV}$ (commonly used FTO workfunction $[71,73,112])$, and tune the cathode workfunction between between $-4.7 \mathrm{eV}$ and $-5.3 \mathrm{eV}$. The efficiency increases while changing workfunction from $-4.7 \mathrm{eV}$ to $-5.0 \mathrm{eV}$. The increased efficiency could be attributed to increased hole transfer from the HTL to the cathode. Further shift in the cathode workfunction does not significantly change the tandem efficiency. Figure 14 summarizes the tandem cell efficiency as function of bottom cell anode and cathode workfunctions. A similar analysis could be done to optimize the top cell contact workfunctions.

For the top cell, both the cathode and anode are desired to be transparent, so that the unabsorbed light is filtered to the bottom cell. On the other hand, in a bottom cell, the bottom contact can be optically opaque. Therefore, the bottom cell cathode contact can be made up of metals, such as gold $(\mathrm{Au})$. For our further analysis, we fix cathode 


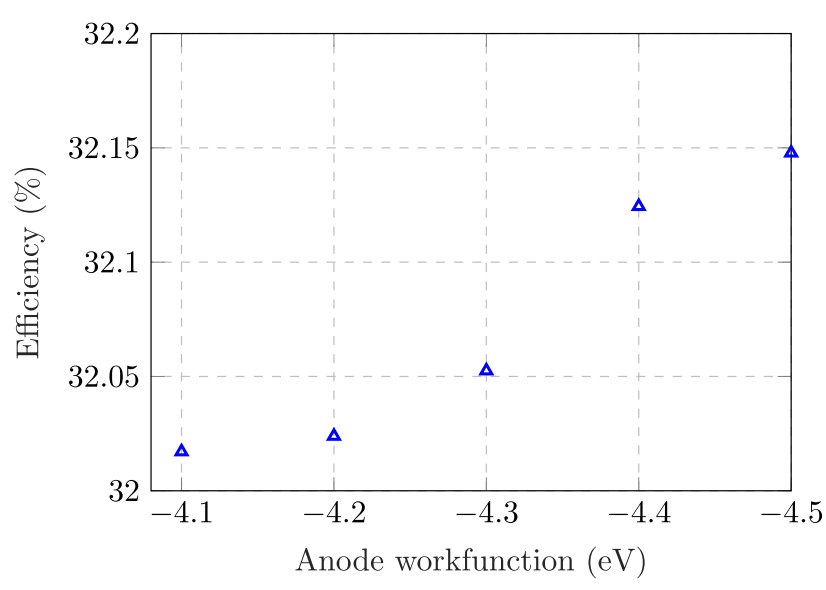

(a)

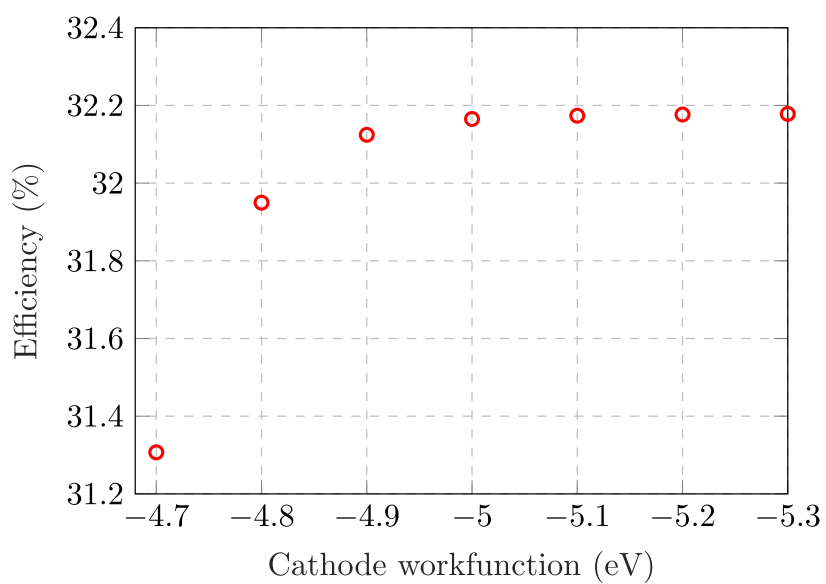

(b)

Fig. 14. (a) Tandem cell efficiency as function of bottom cell anode workfunction at a fixed cathode workfunction of $-4.9 \mathrm{eV}$. (b) Tandem cell efficiency as function of bottom cell cathode workfunction at a fixed anode workfunction of $-4.4 \mathrm{eV}$.

workfunction to be $-5.1 \mathrm{eV}$, which is close to the gold workfunction. For the anode contact, FTO can be used for both the top and bottom cells. Therefore, for further analysis, FTO anode $(-4.4 \mathrm{eV})$ will be considered for both top and bottom cells.

\subsection{Perovskite surface functionalization}

Doping in the charge transport layer is a cumbersome process, and it is sometimes difficult to obtain high doping in charge transport layers. Also, due to limited number of available transparent charge transport layer materials and transparent conductive oxides, it is not always possible to obtain a good energy alignment for all perovskite bandgaps. In that case, the charge injection from the perovskite into the charge transport layers becomes difficult, and an optimum efficiency is not achieved. The charge injection from the perovskite into the charge transport layers could be improved via surface modification of perovskite layer. This technique could be useful to obtain high efficiency even for low-doped charge transport layers. Changing the perovskite energy levels via surface modification near the perovskite/HTL and/or perovskite/ETL interfaces improves the energy alignment and hence the performance of perovskite solar cells [14,113-115]. The perovskite energy levels can be tuned by creating surface dipoles by using self assembled molecules [14,113,114]. The direction of the dipole moments determines the positive and negative shift in the perovskite energy levels near the surface. Figure 15 shows scheme of changing perovskite energy levels near perovskite/HTL interface.

Here, we study the impact of change in the perovskite energy levels near the perovskite/HTL interface. Both the conduction and valence bands are shiffted by the same amount. An upward shift is considered to be a positive shift, and vice versa. Similar to our previous study [14], the change in the perovskite energy levels is modeled by using a $2 \mathrm{~nm}$ buffer region with the material properties same as the perovskite layer, except the shifted

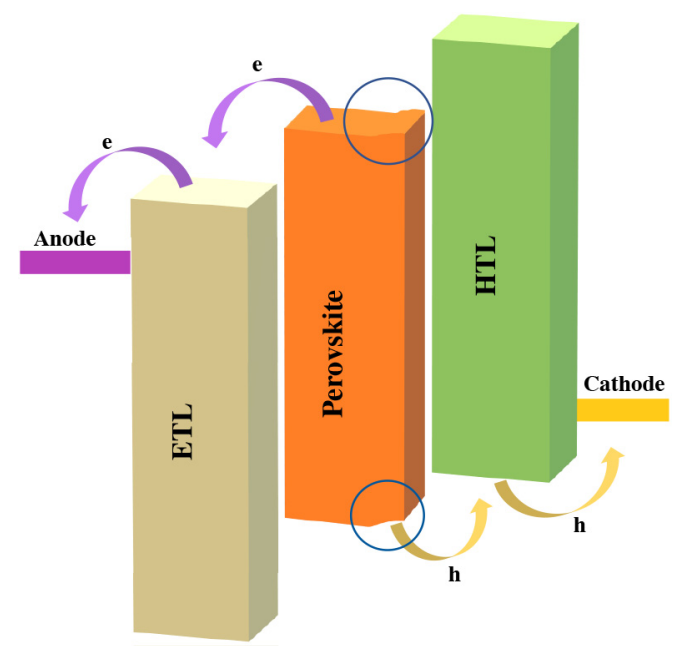

Fig. 15. Perovskite surface energy levels shifting scheme. The regions shown in the blue circles show the shifted conduction and valence bands of the perovskite layer near the perovskite/HTL interface. Both the conduction and valence bands are shifted by the same amount.

valence and conduction bands. First, we study the impact of the perovskite energy level shift in the top cell. At the interface, the perovskite valence and conduction are shifted between $-100 \mathrm{meV}$ and $+40 \mathrm{meV}$ with respect to the bulk perovskite layer. This is observed that the tandem efficiency increases with a negative shift, and decreases with a positive shift. For a negative shift higher than $\simeq-80 \mathrm{meV}$, the tandem efficiency no more increases, as shown in Figure 16a. It can be inferred that, for $\simeq-80 \mathrm{meV}$ of shift, the hole quasi-Fermi level $\left(\mathrm{Q}_{f h}\right)$ of perovskite and the HTL Fermi levels are optimally aligned to result in maximum hole transfer from the perovskite into the HTL.

A similar analysis is done by tuning interface energy levels of the bottom cell perovskite. The top cell perovskite energy levels are brought back to the reference $(0 \mathrm{meV}$ shift), and the bottom perovskite (interface) energy levels 


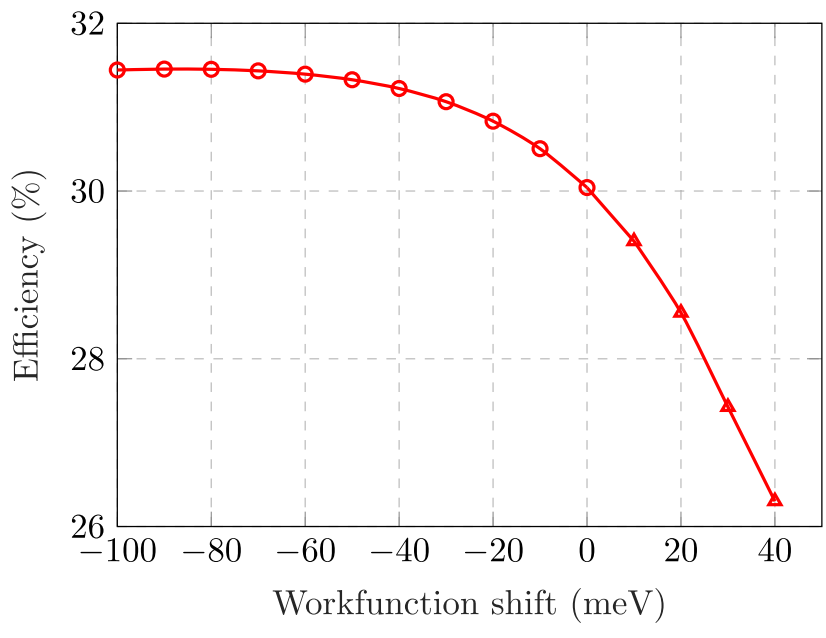

(a)

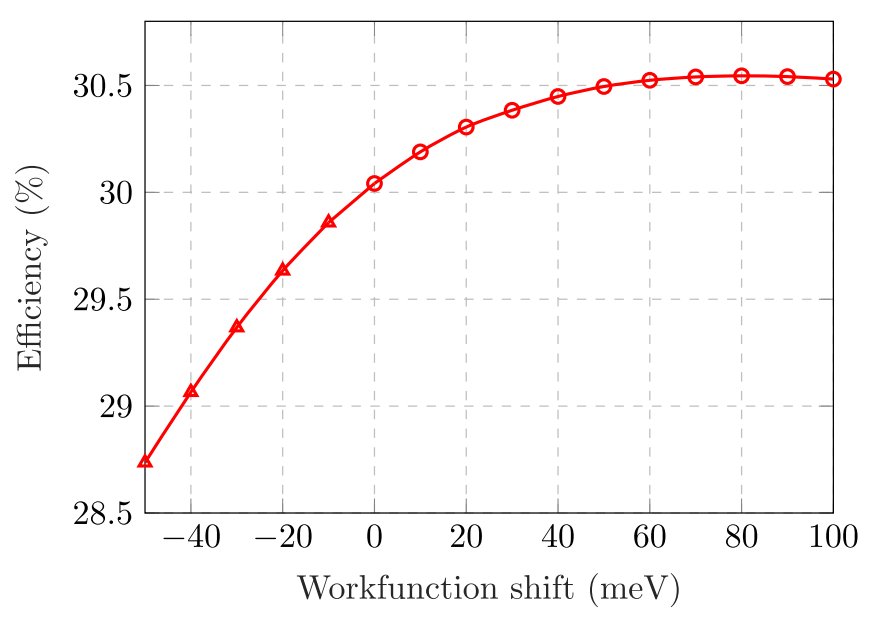

(b)

Fig. 16. (a) Tandem cell efficiency as function of top perovskite energy level shift near the perovskite/HTL interface. (b) Tandem cell efficiency as function of bottom perovskite energy level shift near the perovskite/HTL interface. Both the conduction and valence bands are shifted by the same amount. In contrast to no shift in energy levels, circle and triangle marks show increase and decrease in the efficiency, respectively.

are shifted between $-50 \mathrm{meV}$ and $+100 \mathrm{meV}$. Unlike the case for the top cell, the bottom cell performance improves for a positive shift in the perovskite energy levels. The tandem efficiency of about $30.5 \%$ is obtained for a shift of $+60 \mathrm{meV}$. The efficiency starts decreasing for a shift exceeding $+80 \mathrm{meV}$. A positive shift in the perovskite energy levels brings perovskite $\mathrm{Q}_{f h}$ close to the HTL Fermi level leading to increase hole injection. For the shift exceeding $+80 \mathrm{meV}$, the HTL Fermi level comes to a lower level as compared to the $\mathrm{Q}_{f h}$, which limits the hole transfer from perovskite to HTL. This reduced hole transfer yield results in a poor performing bottom cell, and ultimately to a reduced tandem efficiency.

We have studied the impact of the energy level tuning of top and bottom cell perovskites individually. However, in a tandem cell, both the top and bottom cell perovskite energy levels can be modified to obtain the optimum tandem efficiency. Surface modification is a powerful tool in $4 \mathrm{~T}$ tandem configuration as there is no need of current matching between the top and bottom cells. However, the trend in the efficiency with respect to the perovskite energy levels depends on several other parameters, i.e., initial energy levels of the perovskite layer, valence band of HTL, doping level in HTL and the cathode Fermi level. Therefore, a different device architecture can result in a different trend while tuning the perovskite energy levels.

\section{Conclusion}

In conclusion, we have investigated all-perovskite $4 \mathrm{~T}$ tandem cell efficiency as a function of subcell thicknesses, bandgaps, contact workfunctions, perovskite energy level modification and HTL doping. A one-dimensional driftdiffusion model calculates efficiency for ideal devices as well as devices with trap-assisted recombinations. In an ideal case, the $4 \mathrm{~T}$ configuration can achieve power conversion efficiencies up to $37 \%$. Interface and bulk traps play an important role in limiting tandem cell efficiency. For bulktrap time constant $\tau_{n}=\tau_{p}=5 \times 10^{-7}$ and interface trap time constant $\tau_{n}=\tau_{p}=1 \times 10^{-9}$, a $4 \mathrm{~T}$ tandem cell can achieve more than $33 \%$ of practical efficiencies. Optimum output efficiency is obtained for a top cell bandgap of about $1.55 \mathrm{eV}$ and a bottom cell bandgap of about $0.9 \mathrm{eV}$. The optimum top and bottom cell thicknesses are found to be $\simeq 250 \mathrm{~nm}$ and $450 \mathrm{~nm}$, respectively. Experimentally reported top and bottom cells of bandgaps about $1.8 \mathrm{eV}$, and $1.2 \mathrm{eV}$, respectively, can achieve power conversion efficiency about $26 \%$ (considering trap-assisted losses, without energy alignment optimization). Further, the efficiency can be pushed higher by optimizing energy alignment within the subcells, i.e., by using optimized contact workfunctions, doping, and perovskite surface modification. Energy alignment within a subcell determines the charge transport in that cell. Doping in charge transport layers can help improve the charge transport in a subcell and hence the efficiency of the tandem cell. Considering the constant-mobility model for $1.55 \mathrm{eV}$ top cell and $1.0 \mathrm{eV}$ bottom cell, the p-type doping in hole transport layers can improve efficiency by $\simeq 4.5 \%$. However, the impact of doping level also depends on other factors such as choice of bandgaps, individual energy levels of each layer, and the contact workfunctions. Therefore, the doping should be optimized independently depending upon the device architecture and the energy level alignment in a subcell. By using surface modification of perovskite layer, a better charge injection from the perovskite to the charge transport layer can be obtained. The perovskite surface modification could be a powerful tool to achieve an optimum energy alignment even in case of low-doped charge transport layers. 
This work is supported by the TUM International Graduate School of Science and Engineering (IGSSE) under project 11.02 (CONTROL). Also, A.S. acknowledge financial support from German Academic Exchange Service (DAAD) for funding reference 91650212 via funding program 57299294. Authors would also like to thank Kashif Hussain and Dr. Trinetra Mukherjee for their useful discussions.

\section{Author contribution statement}

A. Singh contributed to conceptualization, methodology, simulation, and writing the manuscript. A. Gagliardi contributed to conceptualization, validation, and reviewing and editing the manuscript.

\section{References}

1. J.S. Manser, J.A. Christians, P.V. Kamat, Chem. Rev. 116, 12956 (2016)

2. C. Wehrenfennig, G.E. Eperon, M.B. Johnston, H.J. Snaith, L.M. Herz, Adv. Mater. 26, 1584 (2014)

3. J.Y. Kim, J.-W. Lee, H.S. Jung, H. Shin, N.-G. Park, Chem. Rev. 120, 7867 (2020)

4. I.E. Castelli, J.M. Garca-Lastra, K.S. Thygesen, K.W. Jacobsen, APL Mater. 2, 081514 (2014)

5. K.A. Bush, K. Frohna, R. Prasanna, R.E. Beal, T. Leijtens et al., ACS Energy Lett. 3, 428 (2018)

6. Z. Song, C.L. McElvany, A.B. Phillips, I. Celik, P.W. Krantz et al., Energy Environ. Sci. 10, 1297 (2017)

7. P. Roy, N.K. Sinha, S. Tiwari, A. Khare, Sol. Energy 198, $665(2020)$

8. NREL, Solar cell efficiency chart (Accessed on 31 July 2021)

9. J. Zhang, W. Zhang, H.-M. Cheng, S.R.P. Silva, Mater. Today 39, 66 (2020)

10. F. Gao, Y. Zhao, X. Zhang, J. You, Adv. Energy Mater. 10, $1902650(2020)$

11. A. Singh, F. Matteocci, H. Zhu, D. Rossi, S. Mejaouri, S. Cacovich et al., Solar RRL 5, 2100277 (2021)

12. E. Aydin, M. De Bastiani, S. De Wolf, Adv. Mater. 31, 1900428 (2019)

13. E. Zojer, T.C. Taucher, O.T. Hofmann, Adv. Mater. Interfaces 6, 1900581 (2019)

14. L. Canil, T. Cramer, B. Fraboni, D. Ricciarelli, D. Meggiolaro, A. Singh, M. Liu, M. Rusu, C.M. Wolff, N. Phung et al., Energy Environ. Sci. 14, 1429 (2021)

15. Y. Zhou, J. Hu, Y. Wu, R. Qing, C. Zhang, X. Xu, M. Jiang, J. Photonics Energy 9, 040901 (2019)

16. S. Rühle, Sol. Energy 130, 139 (2016)

17. P. Colter, B. Hagar, S. Bedair, Crystals 8, 445 (2018)

18. M. Yamaguchi, K.-H. Lee et al., J. Phys. D: Appl. Phys. 51, $133002(2018)$

19. S. De Wolf, J. Holovsky, S.-J. Moon, P. Löper, B. Niesen, M. Ledinsky et al., J. Phys. Chem. Lett. 5, 1035 (2014)

20. M. Anaya, G. Lozano, M.E. Calvo, H. Mguez, Joule 1, 769 (2017)

21. J. You, Z. Hong, Y. Yang, Q. Chen, M. Cai, T.-B. Song, C.-C. Chen et al., ACS nano 8, 1674 (2014)

22. Z. Wang, X. Zhu, S. Zuo, M. Chen, C. Zhang, C. Wang et al., Adv. Funct. Mater. 30, 1908298 (2020)
23. M. De Bastiani, A.J. Mirabelli, Y. Hou, F. Gota, E. Aydin, T.G. Allen et al., Nat. Energy 6, 167 (2021)

24. E. Lamanna, F. Matteocci, E. Calabrò, L. Serenelli, E. Salza, L. Martini et al., Joule 4, 865 (2020)

25. Z. Fang, Q. Zeng, C. Zuo, L. Zhang, H. Xiao, M. Cheng et al., Sci. Bull. 66, 621 (2021)

26. S. Xie, R. Xia, Z. Chen, J. Tian, L. Yan, M. Ren et al., Nano Energy 78, 105238 (2020)

27. P. Wang, Y. Zhao, T. Wang, Appl. Phys. Rev. 7, 031303 (2020)

28. M. Daboczi, J. Kim, J. Lee, H. Kang, I. Hamilton, C.-T. Lin et al., Adv. Funct. Mater. 30, 2001482 (2020)

29. D. Zhao, C. Chen, C. Wang, M.M. Junda, Z. Song, C.R. Grice et al., Nat. Energy 3, 1093 (2018)

30. Y. Yao, F. Lv, L. Luo, L. Liao, G. Wang, D. Liu, C. Xu, G. Zhou, X. Zhao, Q. Song, Solar RRL 4, 1900396 (2020)

31. A. Rajagopal, Z. Yang, S.B. Jo, I.L. Braly, P.-W. Liang, H.W. Hillhouse et al., Adv. Mater. 29, 1702140 (2017)

32. G.E. Eperon, T. Leijtens, K.A. Bush, R. Prasanna, T. Green, J.T.-W. Wang et al., Science 354, 861 (2016)

33. Y. Wang, M. Zhang, K. Xiao, R. Lin, X. Luo, Q. Han, H. Tan, J. Semicond. 41, 051201 (2020)

34. T. Leijtens, K.A. Bush, R. Prasanna, M.D. McGehee, Nat. Energy 3, 828 (2018)

35. A. Singh, A. Gagliardi, Sol. Energy 187, 39 (2019)

36. Q. Wali, N.K. Elumalai, Y. Iqbal, A. Uddin, R. Jose, Renew. Sustain. Energy Rev. 84, 89 (2018)

37. H.Q. Tan, X. Zhao, E. Birgersson, F. Lin, H. Xue, Sol. Energy 216, 589 (2021)

38. T. Todorov, O. Gunawan, S. Guha, Mol. Syst. Des. Eng. 1, $370(2016)$

39. D. Zhao, C. Wang, Z. Song, Y. Yu, C. Chen, X. Zhao, K. Zhu, Y. Yan, ACS Energy Lett. 3, 305 (2018)

40. S. Moghadamzadeh, I.M. Hossain, S. Gharibzadeh, T. Abzieher, H. Pham, H. Hu et al., J. Mater. Chem. A 8, 24608 (2020)

41. B. Abdollahi Nejand, I.M. Hossain, M. Jakoby, S. Moghadamzadeh, T. Abzieher, S. Gharibzadeh et al., Adv. Energy Mater. 10, 1902583 (2020)

42. M.I. Hossain, W. Qarony, S. Ma, L. Zeng, D. Knipp, Y.H. Tsang, Nano-Micro Lett. 11, 58 (2019)

43. C. Honsberg, S. Bowden, Photovoltaic education network (2021), https://www.pveducation.org/pvcdrom/tandem-cells

44. G.E. Eperon, M.T. Hörantner, H.J. Snaith, Nat. Rev. Chem. 1, 0095 (2017)

45. A. De Vos, J. Phys. D: Appl. Phys. 13, 839 (1980)

46. A. Gagliardi, M.A. der Maur, D. Gentilini, F. di Fonzo, A. Abrusci et al., Nanoscale 7, 1136 (2015)

47. M.A. der Maur, G. Penazzi, G. Romano, F. Sacconi, A. Pecchia, A. Di Carlo, IEEE Trans. Electr. Dev. 58, 1425 (2011)

48. A. Gagliardi, S. Wang, T. Albes, Org. Electron. 59, 171 (2018)

49. M. Darwish, A. Gagliardi, J. Phys. D: Appl. Phys. 53, $105102(2019)$

50. A. Singh, A. Gagliardi, in 2020 IEEE 20th International Conference on Nanotechnology (IEEE-NANO) (IEEE, 2020), pp. 227-232

51. A. Singh, E. Radicchi, S. Fantacci, F. Nunzi, F. De Angelis et al., J. Phys. Chem. C 123, 14955 (2019)

52. A. Singh, W. Kaiser, A. Gagliardi, Sol. Energy Mater Sol. 221, 110912 (2021) 
53. J.M. Richter, K. Chen, A. Sadhanala, J. Butkus, J.P. Rivett, R.H. Friend et al., Adv. Mater. 30, 1803379 (2018)

54. E.M. Hutter, M.C. Gélvez-Rueda, A. Osherov, V. Bulović, F.C. Grozema, S.D. Stranks et al., Nat. Mater. 16, 115 (2017)

55. J.I. Pankove, Optical Processes in Semiconductors (Courier Corporation, 1975)

56. X. Meng, Y. Wang, J. Lin, X. Liu, X. He, J. Barbaud, T. Wu, T. Noda, X. Yang, L. Han, Joule 4, 902 (2020)

57. C. Ran, W. Gao, J. Li, J. Xi, L. Li, J. Dai, Y. Yang, X. Gao, H. Dong, B. Jiao et al., Joule 3, 3072 (2019)

58. S. Shao, J. Liu, G. Portale, H.-H. Fang, G.R. Blake, G.H. ten Brink et al., Adv. Energy Mater. 8, 1702019 (2018)

59. Y. Wu, F. Xie, H. Chen, X. Yang, H. Su, M. Cai, Z. Zhou, T. Noda, L. Han, Adv. Mater. 29, 1701073 (2017)

60. S. Tao, I. Schmidt, G. Brocks, J. Jiang, I. Tranca, K. Meerholz, S. Olthof, Nat. Commun. 10, 2560 (2019)

61. S. Selberherr, Analysis and Simulation of Semiconductor Devices (Springer Science \& Business Media, 2012)

62. J. Simmons, G. Taylor, Phys. Rev. B 4, 502 (1971)

63. A.A. Said, J. Xie, Q. Zhang, Small 15, 1900854 (2019)

64. L.-L. Deng, S.-Y. Xie, F. Gao, Adv. Electron. Mater. 4, $1700435(2018)$

65. P.-K. Kung, M.-H. Li, P.-Y. Lin, Y.-H. Chiang, C.-R. Chan, T.-F. Guo et al., Adv. Mater. Interfaces 5, 1800882 (2018)

66. R. Singh, P.K. Singh, B. Bhattacharya, H.-W. Rhee, Appl. Mater. Today 14, 175 (2019)

67. Y. Xia, S. Dai, J. Mater. Sci. : Mater. Electron. 32, 12746 (2021)

68. Y. He, G. Galli, Chem. Mater. 29, 682 (2017)

69. J.N. Wilson, J.M. Frost, S.K. Wallace, A. Walsh, APL Mater. 7, 010901 (2019)

70. M. Samiee, S. Konduri, B. Ganapathy, R. Kottokkaran, H. A. Abbas, A. Kitahara et al., Appl. Phys. Lett. 105, 153502 (2014)

71. A. Andersson, N. Johansson, P. Bröms, N. Yu, D. Lupo, W.R. Salaneck, Adv. Mater. 10, 859 (1998)

72. L. Chkoda, C. Heske, M. Sokolowski, E. Umbach, F. Steuber, J. Staudigel et al., Synth. Met. 111, 315 (2000)

73. R. Schlaf, H. Murata, Z. Kafafi, J. Electron Spectros. Relat. Phenomena. 120, 149 (2001)

74. A. Gankin, E. Mervinetsky, I. Alshanski, J. Buchwald, A. Dianat, R. Gutierrez et al., Langmuir 35, 2997 (2019)

75. A. Klein, C. Körber, A. Wachau, F. Säuberlich, Y. Gassenbauer, S.P. Harvey et al., Materials 3, 4892 (2010)

76. X. Xie, G. Liu, C. Xu, S. Li, Z. Liu, E.-C. Lee, Org. Electr. 44, $120(2017)$

77. G. Ligorio, N. Zorn Morales, E.J. List-Kratochvil, Appl. Phys. Lett. 116, 241603 (2020)

78. D. Han, C. Wu, Y. Zhao, Y. Chen, L. Xiao, Z. Zhao, ACS Appl. Mater. Interfaces 9, 42029 (2017)

79. M.G. Helander, M. Greiner, Z. Wang, W.M. Tang, Z. Lu, J. Vac. Sci. Technol. A 29, 011019 (2011)

80. M.B. Johnston, L.M. Herz, Acc. Chem. Res. 49, 146 (2016)

81. C. Motta, F. El-Mellouhi, S. Sanvito, Sci. Rep. 5, 1 (2015)

82. F. Arca, M. Loch, P. Lugli, IEEE J. Photovolt. 4, 1560 (2014)
83. H. Wang, X. Wang, P. Fan, X. Yang, J. Yu, Int. J. Photoenergy 2015 (2015)

84. V.D. Mihailetchi, J.K. van Duren, P.W. Blom, J.C. Hummelen, R.A. Janssen, J.M. Kroon et al., Adv. Funct. Mater. 13, 43 (2003)

85. S. Joshi, M. Mudigere, L. Krishnamurthy, G. Shekar, Chem. Pap. 68, 1584 (2014)

86. P.-J. Liu, Z.-J. Yao, V.M.H. Ng, J.-T. Zhou, Z.-H. Yang, L.-B. Kong, Acta Metall. Sin. (Engl. Lett.) 31, 171 (2018)

87. M. Tyagi, M. Tomar, V. Gupta, Anal. Chim. Acta 726, $93(2012)$

88. A. Huang, J. Zhu, J. Zheng, Y. Yu, Y. Liu, S. Yang, S. Bao, L. Lei, P. Jin, J. Mater. Chem. C 4, 10839 (2016)

89. S. Kang, Y. Yi, C. Kim, S. Cho, M. Noh, K. Jeong et al., Synth. Met. 156, 32 (2006)

90. R. Motoyoshi, T. Oku, A. Suzuki, K. Kikuchi, S. Kikuchi, B. Jeyadevan, J. Cuya, Adv. Mater. Sci. Eng. 2010, 562842 (2010)

91. J.J. Kwiatkowski, J.M. Frost, J. Nelson, Nano Lett. 9, 1085 (2009)

92. A. Labrunie, J. Gorenflot, M. Babics, O. Aleveque, S. Dabos-Seignon, A.H. Balawi et al., Chem. Mater. 30, 3474 (2018)

93. M. Ye, C. He, J. Iocozzia, X. Liu, X. Cui, X. Meng et al., J. Phys. D: Appl. Phys. 50, 373002 (2017)

94. E.S. Muckley, C.B. Jacobs, K. Vidal, J.P. Mahalik, R. Kumar, B.G. Sumpter, I.N. Ivanov, ACS Appl. Mater. Interfaces 9, 15880 (2017)

95. T. Kirchartz, J.A. Márquez, M. Stolterfoht, T. Unold, Adv. Energy Mater. 2020, 1904134 (2020)

96. H. Yu, J. Ryu, J.W. Lee, J. Roh, K. Lee, J. Yun et al., ACS Appl. Mater. Interfaces 9, 8113 (2017)

97. C. Kuang, G. Tang, T. Jiu, H. Yang, H. Liu, B. Li et al., Nano Lett. 15, 2756 (2015)

98. T.S. Sherkar, C. Momblona, L. Gil-Escrig, H.J. Bolink, L.J.A. Koster, Adv. Energy Mater. 7, 1602432 (2017)

99. Z. Hu, Z. Lin, J. Su, J. Zhang, J. Chang, Y. Hao, Solar RRL 3, 1900304 (2019)

100. C. Wang, Z. Song, C. Li, D. Zhao, Y. Yan, Adv. Funct. Mater. 29, 1808801 (2019)

101. A.-F. Castro-Méndez, J. Hidalgo, J.-P. Correa-Baena, Adv. Energy Mater. 9, 1901489 (2019)

102. G.-J.A. Wetzelaer, M. Scheepers, A.M. Sempere, C. Momblona, J. Ávila, H.J. Bolink, Adv. Mater. 27, 1837 (2015)

103. M.I.H. Ansari, A. Qurashi, M.K. Nazeeruddin, J. Photochem. Photobiol. C 35, 1 (2018)

104. S. Shao, M.A. Loi, Adv. Mater. Interfaces 7, 1901469 (2020)

105. J. Chen, N.-G. Park, Adv. Mater. 31, 1803019 (2019)

106. T.S. Sherkar, C. Momblona, L. Gil-Escrig, J. Ávila, M. Sessolo, H.J. Bolink et al., ACS Energy Lett. 2, 1214 (2017)

107. V.M. Le Corre, M. Stolterfoht, L. Perdigón Toro, M. Feuerstein, C. Wolff, L. Gil-Escrig et al., ACS Appl. Energy Mater. 2, 6280 (2019)

108. S.-J. Yoo, J.-J. Kim, Macromol. Rapid Commun. 36, 984 (2015) 
109. M. Fang, C. Zhang, Q. Chen, Appl. Surf. Sci. 385, 28 (2016)

110. A. Alves, D. Gomes, J. Silva, G. Silva, Appl. Surf. Sci. 279, $67(2013)$

111. S. Huang, Q. Dong, Y. Shi, L. Duan, L. Wang, Chem. Eng. J. 394, $125024(2020)$

112. A.K. Mishra, R. Shukla, SN Appl. Sci. 2, 321 (2020)
113. H. Dong, J. Xi, L. Zuo, J. Li, Y. Yang, D. Wang et al., Adv. Funct. Mater. 29, 1808119 (2019)

114. Z. Wu, Z. Liu, Z. Hu, Z. Hawash, L. Qiu, Y. Jiang et al., Adv. Mater. 31, 1804284 (2019)

115. T. Chen, G. Tong, E. Xu, H. Li, P. Li, Z. Zhu et al., J. Mater. Chem. A 7, 20597 (2019)

Cite this article as: Ajay Singh, Alessio Gagliardi, Device simulation of all-perovskite four-terminal tandem solar cells: towards $33 \%$ efficiency, EPJ Photovoltaics 12, 4 (2021) 